\title{
LAS OBLIGACIONES DEL PORTEADOR EN EL CONTRATO DE TRANSPORTE MARÍTIMO DE MERCANCÍAS
}

\author{
CARRIER'S OBLIGATIONS IN CARRIAGE OF GOODS BY SEA \\ CONTRACTS
}

\section{FERNANDO JimÉneZ VALDERRAMA ${ }^{1}$}

\begin{abstract}
RESUMEN: El derecho del transporte de mercancías por mar evolucionó desde un marco de libertad absoluta a un sistema donde hay límites para las partes en los contratos de transporte. Legislación reciente en derecho continental y en el common law (como la Ley de Transporte Marítimo de 1949 en España y el Código de Comercio en Colombia) establecen límites a las partes cuando celebran contratos de transporte marítimo. Tratados internacionales, como las Reglas de La Haya Visby, las Reglas de Hamburgo y las Reglas de Rotterdam, también regulan la materia siguiendo este propósito. Soluciones dadas por derechos nacionales, provenientes del common law y del derecho continental, debe ser aplicadas teniendo en cuenta el propósito de uniformidad del derecho marítimo. La regulación española del contrato de fletamentotransporte debe ser aplicada considerando una única y fundamental obligación de transporte de mercancías en vez de cualquier otra naturaleza de arrendamiento. La obligación de transporte debe ser entendida como compleja. Existen distintos deberes, como la custodia y entrega de la mercancía, que el deudor debe realizar a fin de alcanzar el propósito final del contrato.
\end{abstract}

Palabras clave: Contratos de transporte de mercancías por mar, obligaciones del porteador en el transporte marítimo, Ley de Transporte Marítimo española, Código de Comercio colombiano, Reglas de La Haya Visby, Reglas de Hamburgo, Reglas de Rotterdam.

ABSTRACT: The law of carriage of goods by sea has evolved from an absolute freedom framework into a system where there are limits for parties in transportation contracts. In the continental and common law recent legislations (like the Maritime Transportation Act 1949 in Spain and Commercial Code in Colombia) have been established limits to parties when they perform maritime transportation agreements. The International treaties, like the Hague Visby Rules, the Hamburg Rules and the Rotterdam Rules, regulated the matter following this purpose. Solutions given by national law, in common law and continental law, must be applied taking into account the uniformity purpose of maritime regulations. The Spanish regulation of the affreighment - transportation contract must be applied considering a fundamental and unique obligation to transport goods instead of any other rental nature.

\footnotetext{
1 Profesor y Jefe del Área de Derecho Privado y de la Empresa de la Facultad de Derecho de la Universidad de La Sabana (Colombia). Abogado. Doctor en Derecho de la Universidad de Salamanca (España). Máster en Derecho de la Unión Europea por la Universidad Carlos III de Madrid (España). Ha sido profesor en las Universidades San Pablo-CEU, Complutense y Carlos III de Madrid y Director del Instituto Europeo de Estudios Marítimos. Es miembro de la Asociación Española de Derecho Marítimo, del Ilustre Colegio de Abogados de Madrid (España). Este artículo ha sido elaborado en el marco del proyecto de investigación realizado en la Universidad de La Sabana titulado: "Transformaciones del ordenamiento jurídico colombiano a partir de la vigencia de los Tratados de Libre Comercio con los Estados Unidos y la Unión Europea: el transporte marítimo, la protección de la propiedad industrial, la contratación pública, la actividad financiera y aseguradora y los derechos laborales de los trabajadores".

Dirección postal: Facultad de Derecho, Universidad de la Sabana, Campus del Puente del Común, Autopista Norte, vía Chía, km. 7, Bogotá (Colombia). Correo electrónico: fernando.jimenez@unisabana.edu.co
} 
Carriage obligation must be understood as a complex duty from shipowner. There are several duties, such care and delivery of transported goods, that the debtor must perform in order to achieve the final purpose of the contract.

Key words: Carriage of goods by sea contracts, carrier obligations in maritime transportation, Spanish Maritime Transportation Act, Colombian Commercial Code, Hague Visby Rules, Hamburg Rules, Rotterdam Rules.

\section{INTRODUCCIÓN}

La pluralidad de fuentes normativas reguladoras del contrato de transporte marítimo de mercancías, unas provenientes del ámbito nacional y otras del ámbito internacional ${ }^{2}$, hacen que el tratamiento de este tipo de contratos resulte complejo.

Al tratarse de una actividad económica eminentemente internacional, se hace inevitable la confluencia de ordenamientos jurídicos provenientes de familias jurídicas diversas, predominando, en el caso del mundo occidental, por un lado, los ordenamientos que pertenecen al denominado common law $w^{3}$, por otro, los vinculados al llamado derecho continental europeo.

Un interpretación adecuada de las distintas fuentes normativas resulta necesaria tanto en el ámbito del contrato de transporte marítimo de mercancías en general como, particularmente, en las obligaciones que surgen por la creación de este tipo contractual. En este

\footnotetext{
${ }^{2}$ En el caso español la Ley de Transporte Marítimo de 1949 y el Código de Comercio español y, en el caso colombiano, el Código de Comercio colombiano. En el ámbito internacional nos referimos a los sucesivos convenios que han regulado la materia, particularmente las denominadas Reglas de La Haya-Visby, Reglas de Hamburgo y las recientemente aprobadas Reglas de Rotterdam.

3 El planteamiento general dado por el derecho británico coincide en esencia con la consideración del transporte como eje central del cual se articulan los contratos de fletamento (affreightment). La existencia de una misma realidad y la necesidad de plantear soluciones jurídicas racionales ha hecho coincidir en sustancia el sistema inglés con las soluciones dadas por el derecho continental europeo. El planteamiento británico aunque menos elaborado conceptualmente, hace girar los contratos de transporte marítimo de mercancías en torno a la figura del fletamento, que puede nacer, bien sea de un compromiso del naviero para transportar mercancías por mar, o bien un compromiso para proveer un buque para realizar dicho transporte. Tradicionalmente se admite que el contrato de fletamento puede asumir una de dos formas de acuerdo con la documentación contractual que se utilice al momento de su celebración. De esta manera podemos hablar de póliza de fletamento (charterparty) o bien de conocimientos de embarque (bills of lading). En general, mediante el contrato contenido en un charterparty, el naviero se obliga a ofrecer la capacidad completa de su buque para un viaje particular o para un específico periodo de tiempo, considerándose en uno u otro caso voyage-charterparty o time-charterparty, respectivamente. Cada tipo de contrato obedece a la necesidad de cumplir una finalidad diferente, mientras el documento en bills of lading es utilizado para el transporte de mercancías principalmente en servicio de línea regular, ofreciendo el naviero este servicio de transporte con indiferencia de la mercancía y la persona del cargador, en el formalizado a través de un charterparty, el fletador toma un buque del fletante y lo utiliza para el transporte de mercancías en la realización de un determinado viaje o bien por un específico período de tiempo. A través del charterparty tanto las empresas armadoras con déficit temporal en disponibilidad de buques, como las empresas comerciales a gran escala (por ejemplo, petroleras), necesitadas de transportar sus productos, pero no interesadas en asumir directamente la realización de la travesía marítima, pueden acceder a buques de empresas fletantes para satisfacer sus necesidades temporales. Por el contrario las empresas de menores dimensiones, cuyo único interés radica en trasladar sus mercancías de un sitio a otro, sin importar el buque a través del cual se realice en la medida que cumpla con las condiciones adecuadas y de seguridad, optan por la celebración de un contrato de transporte documentado en conocimiento de embarque.
} 
artículo pretendemos analizar la estructura general de las obligaciones que surgen en estos contratos, con particular énfasis en los deberes de custodia y entrega de la mercancía.

\section{LA NORMATIVA REGULADORA DEL CONTRATO DE TRANSPORTE MARÍTIMO DE MERCANCÍAS}

Actualmente son normativas vigentes en España, reguladoras del transporte marítimo de mercancías, las contenidas en el Código de Comercio y en las Reglas de La Haya-Visby ${ }^{4}$, introducidas en la legislación interna a través de la Ley de Transporte Marítimo de Mercancías de 1949, teniendo en cuenta los aspectos reformados por los Protocolos de 23 de febrero de 1968 y 21 de diciembre de 1979, modificatorios del Convenio de Bruselas de 19245.

Colombia, por su parte, no ha ratificado ninguno de estos convenios internacionales, con lo cual la única normativa vigente es la interna, principalmente consagrada en el Código de Comercio, si bien en la práctica internacional los operadores de transporte regulan con frecuencia sus relaciones comerciales utilizando los Convenios anteriormente referidos, atendiendo al reconocimiento a la autonomía privada y la facultad de las partes en un contrato para establecer el ordenamiento jurídico que regulará sus relaciones ${ }^{6}$.

Si consideramos que cada una de las normativas antes mencionadas mantiene actualmente su vigencia, el primer punto a dilucidar hace referencia a su coordinación e integración al momento de regular el transporte marítimo de mercancías. En un nivel general, podemos derivar la existencia de un doble régimen que de ninguna manera es excluyente,

\footnotetext{
${ }^{4}$ Cuando denominamos la normativa internacional vigente en materia de transporte marítimo como Reglas de La Haya-Visby, nos referimos al Convenio de Bruselas de 1924, modificado por los protocolos de 23 de febrero de 1968 (Reglas de Visby) y de 21 de diciembre de 1979. Como sabemos, el Convenio de Bruselas de 1924, norma internacional reguladora del transporte marítimo de mercancías en materia de conocimiento de embarque, fue ratificado por España el 2 de junio de 1930 (Gaceta núm. 212 de 31 de julio de 1930). El mismo Convenio establece en el texto del protocolo de la firma el procedimiento de incorporación en la legislación nacional: "Las Altas Partes contratantes podrán dar efecto a este Convenio, ya dándole fuerza de ley, ya introduciendo en su legislación nacional las reglas adoptadas por el Convenio, en forma apropiada a esta legislación". A este respecto el gobierno español no solamente ratificó el Convenio sino que lo incorporó a su legislación interna mediante una ley (Ley de Transporte Marítimo de Mercancías de 1949). Posteriormente, los Protocolos modificativos del Convenio de Bruselas, de 1968 y 1979, fueron también ratificados por España (BOE de 11 de febrero de 1984) aunque no incorporados a través de una ley. A pesar de la no promulgación legal, que reprodujera dichos protocolos, estos se pueden considerar vigentes vía artículo 96, 1 de la Constitución Española. De esta forma podemos concluir que la normativa actualmente vigente en España en materia de transporte marítimo de mercancías bajo conocimiento de embarque está constituida por la Ley de Transporte Marítimo de Mercancías de 1949, que incorpora el Convenio de Bruselas, modificada parcialmente por los protocolos modificatorios de dicho Convenio de fechas 1968 y 1979. Cfr. Sánchez Calero (2004) p. 528; Broseta (2012) p. 196.

5 Si bien España ratificó el 19 de enero de 2011 el Convenio de las Naciones Unidas sobre el Contrato de Transporte Internacional de Mercancías Total o Parcialmente Marítimo (Reglas de Rotterdam 2008), esta normativa aún no está en vigor puesto que el Convenio exige de la ratificación de al menos 20 países. Hasta ahora solo dos países han ratificado el Convenio (España y Togo).

${ }^{6}$ Igualmente debemos advertir que en el sistema de fuentes del derecho colombiano podrán resultar aplicables los tratados o convenios internacionales no ratificados por Colombia, la costumbre mercantil internacional que reúna las condiciones del artículo $3^{\circ}$ del Código de Comercio, así como los principios generales del derecho comercial, cuando, según el artículo 7 del mencionado código, "no puedan resolverse conforme a las reglas precedentes" (estas son las establecidas en los artículos del 1 al 6 de la normativa codificada).
} 
aunque sí complementario. En el caso español el primer lugar lo ocuparía la legislación con carácter especial, es decir la Ley de Transporte Marítimo de Mercancías de 1949, la cual ha establecido en sus artículos 1 y $2^{7}$, un ámbito de aplicación muy específico.

Las relaciones jurídicas reguladas por la ley se someten a lo dispuesto en ella de forma imperativa, pudiendo las partes regular aquellos aspectos no tratados expresamente por la ley que se imponen a los contratantes. Por su parte el Código de Comercio español se aplicará de manera subsidiaria, esto es, entrará en juego para regular aquellas situaciones en las cuales no existe ni norma imperativa especial, ni expresa voluntad de las partes sobre un determinado punto, y en la medida que la norma aplicable sea congruente con la finalidad de transporte consagrada por el fletamento regulado en el Código de Comercio español ${ }^{8}$.

En el caso colombiano, no existe una ley especial que regule la materia como sucede en España, por lo cual la regulación establecida en el Código de Comercio resulta aplicable a las relaciones de transporte marítimo de mercancías. En general, la vocación del Código colombiano, como la de sus homólogos del derecho latino, es esencialmente sustitutiva de la voluntad contractual, sin embargo debemos afirmar que aunque regla general existen algunos puntos en los que el Código de Comercio colombiano9 (artículo 4º) manifiesta su carácter imperativo ${ }^{10}$.

\footnotetext{
7 Art. 1: "La presente ley tiene por objeto regular las relaciones entre los elementos interesados en el transporte de mercancías por mar, y se aplicará solamente al contrato de transporte internacional, formalizado en las condiciones que expresa el artículo siguiente, a las mercancías que en él se mencionan, y por el tiempo transcurrido desde la carga de las mercancías hasta su descarga, realizadas estas operaciones por los medios propios del barco, entendiéndose que cuando se empleen medios ajenos al mismo el contrato empezará a regir cuando la mercancía se encuentra a bordo del buque". Art. 2: "Por contrato de transporte, a los efectos de la presente Ley, ha de entenderse únicamente el contrato de porte formalizado en un conocimiento o en cualquier documento similar que sirva como título para el transporte de mercancías por mar, aplicándosele igualmente al conocimiento o documento similar emitido en virtud de una póliza de fletamento, a contar desde el momento en que ese documento regula las relaciones del porteador y del tenedor del conocimiento. Por mercancías, los bienes, objetos y artículos de cualquier clase, con excepción de los animales vivos y del cargamento que, según el contrato de transporte, se declara colocado sobre cubierta, y es, efectivamente, transportado así. Y porteador, el naviero, armador o fletador comprometido en un contrato de transporte con un cargador".

${ }^{8}$ Las normas que regulan este tema en el actual Código de Comercio, que a su vez tienen un antecedente directo en las reglas establecidas por el Código de Comercio de 1829, fueron elaboradas en un momento histórico en el cual no se distinguían los diferentes tipos contractuales a través de los cuales se realiza el transporte marítimo de mercancías. Por ello, al momento de aplicarlas, debe tenerse presente este hecho con la finalidad de interpretar como elemento esencial de la institución fletamentaria el transporte (es decir como fletamentotransporte).

9 En adelante CCo col.

10 El artículo 994 CCo. col establece que “Cuando el gobierno lo exija, el transportador deberá tomar por cuenta propia o por cuenta del pasajero o del propietario de la carga, un seguro que cubra a las personas y las cosas transportadas contra los riesgos inherentes al transporte. El transportador no podrá constituirse en asegurador de su propio riesgo o responsabilidad. El gobierno reglamentará los requisitos, condiciones, amparos y cuantías del seguro previsto en este artículo, el cual será otorgado por entidades aseguradoras, cooperativas de seguros, legalmente establecidas". Igualmente, la normativa establecida en el artículo 1031 CCo. col sobre indemnización por pérdida total o parcial de la mercancía tiene carácter imperativo, así como los artículos 1612 y 1618 del CCo. col que impiden la modificación de las reglas relativas a la exoneración y limitación de la responsabilidad del porteador en el transporte de cosas en general, salvo cuando se trate de aumentar su responsabilidad (art. 1612), o bien supuestos no relativos a la responsabilidad por el peso, cantidad, número, identidad, naturaleza, calidad y estado de la mercancía al momento de recibirla (art. 1618).
} 


\section{LA OBLIGACIÓN DE TRANSPORTE COMO EJE CENTRAL DEL CONTRATO DE TRANSPORTE MARÍTIMO DE MERCANCÍAS}

El establecimiento de la obligación de traslado y entrega en destino de las mercancías, como prestación fundamental dentro de la estructura del contrato de transporte marítimo de mercancías, es el hecho que marca la distinción y el origen del contrato de transporte autónomo de otras figuras como el fletamento y formas asociativas. Históricamente este hecho coincide con la evolución de las formas de realización del transporte marítimo desde tipos asociativos, en los cuales existía una participación de todos los integrantes en la ejecución del transporte marítimo, hacia formas contractuales, en las cuales una de las partes es la que asume la obligación de traslado frente a otra que realiza la contraprestación del pago del precio ${ }^{11}$. Igualmente, en el campo de los documentos acreditativos del contrato de transporte, este cambio coincide con el reemplazo del cartulario, como documento que prueba la recepción de las mercaderías, por el conocimiento de embarque ${ }^{12}$. Por otro lado, la obligación de transporte como caracterizadora de este contrato, fue recibida y mantenida por la tradición jurídica española, a diferencia de otros ordenamientos jurídicos, como el francés, en los cuales se consideró el fletamento como un arrendamiento ${ }^{13}$.

No solamente consideraciones de carácter histórico y de tradición jurídica nos llevan a entender la obligación de transporte como fundamental del contrato de transporte marítimo de mercancías. La realidad de la contratación respalda esta afirmación: el fin económico que persigue el cargador al pactar el contrato es el traslado de la mercancía de un puerto a otro para recibirlas en las mismas condiciones en que las entregó. Parece entonces lógico que este hecho económico nos señale como primer aspecto relativo del contenido obligacional del contrato su finalidad de transporte ${ }^{14}$.

De acuerdo con lo anterior, debemos afirmar que la primera y esencial prestación que surge para el naviero o porteador frente al cargador se refiere al transporte de las mercancías recibidas $^{15-16}$. De esta manera, al igual que sucede con los contratos comerciales de

11 Girón Tena p. 9. Brunetti (1950): pp. 151-152 y Peláez (1982): pp. 107 y ss.

12 Cfr. Rubio (1953) p. 22.

13 Recordemos que en la Ordenanza Francesa de 1681 se establece un concepto muy amplio de fletamento en el Libro III, Título I, art. 1.: "toute convention pour le louage d'un vaisseau, appellée Charter-Partie, affretement ou nolissement..." interpretado doctrinalmente como un arrendamiento. Cfr. PARdessus (1845) p. 358; Rubio (1953) pp. 25 y ss.; Ménager (1960) p. 182.

14 A pesar de que este es un presupuesto esencial para el análisis de las obligaciones del contrato, la doctrina ha preferido evitarlo, y acudir directamente a los textos positivos para, sobre su base, establecer un sistema de obligaciones que reproduce los distintos deberes que vinculan al porteador en la relación jurídica. Se evita así una conceptualización del tema que sería muy útil para tener una visión global del contrato, no sometida a la vigencia ocasional de una determinada normativa. Cfr. Matilla (1988) pp. 144 y ss.; SÁnChez-Calero (1957) pp. 48 y ss.; Echevarría (1983) p. 56; Chaveau (1958) pp. 493 y ss.; Hernández Martí (1984) pp. 31 y ss.

15 Entendemos la obligación de transporte como comprensiva de diversas conductas que debe realizar el porteador a fin de obtener el resultado del traslado de la mercancía. Así por ejemplo, el deber de realizar el transporte en un determinado plazo, la obligación de custodia de las mercancías y de su entrega al momento del arribo, según las condiciones que se hayan pactado.

16 De igual manera, en el transporte aéreo de pasajeros, el transportista asume una doble obligación: transportar al pasajero de un lugar a otro, en el plazo convenido y por la ruta pactada, y realizar el transporte sin que 
transporte en general, con el perfeccionamiento de este negocio jurídico surge una obligación fundamental en virtud de la cual el porteador se compromete a trasladar las mercancías objeto del transporte desde el puerto de partida hasta el puerto de destino, en el plazo y las condiciones pactadas, entregándolas en las mismas condiciones en que las recibió ${ }^{17}$. Este punto de partida, aunque parece evidente dentro de la estructura de otros contratos comerciales de transporte, no lo es tanto en esta figura jurídica, debido especialmente a la amplia discusión que doctrinalmente se ha producido respecto a la naturaleza jurídica de los contratos de utilización del buque. Cuando afirmamos que la obligación fundamental de este contrato es el traslado de las mercancías de un puerto a otro, estamos optando por la tesis que sostiene que el contrato de fletamento consagrado por el Código de Comercio español incorpora en todo caso una finalidad de transporte, antes que de arrendamiento.

Por otra parte, en lo que respecta a la Ley española de Transporte Marítimo de 1949, a pesar de que su normativa no establece de una manera expresa la obligación de transporte como fundamental en el contrato de transporte marítimo de mercancías, luego del examen de su articulado no podríamos llegar a una conclusión diferente que la de entender la obligación de transporte como centro de todo la estructura obligacional del contrato. El sistema de responsabilidad que establece esta ley solo puede entenderse partiendo de la base de una obligación de transporte como integradora de las diferentes prestaciones a las que está obligado el porteador, dentro de las cuales se pueden incluir el deber de proveer la navegabilidad del buque, la custodia y conservación de la mercancía y su restitución, luego de realizado el transporte, en el puerto de destino.

En lo que respecta al derecho colombiano, hemos mencionado que el núcleo regulador del contrato de transporte marítimo de mercancías se encuentra en la normativa pertinente del Código de Comercio. El artículo 981 del Código de Comercio colombiano establece con claridad la posición central de la obligación de transporte al afirmar que "el transporte es un contrato por medio del cual una de las partes se obliga para con otra, a cambio de un precio, a conducir de un lugar a otro, por determinado medio y el plazo fijado, personas o cosas y a entregar estas al destinatario".

Otras normas del código reiteran con claridad la obligación de transporte como la característica del porteador. Así el artículo 982 CCo. col establece que "el transportador estará obligado... 1. En el transporte de cosas a recibir, conducirlas y entregarlas en el estado en que las reciba..."; el artículo 1008 CCo. col define "transportador" como "la persona que se obliga a recibir, conducir y entregar las cosas objeto del contrato...”. Particularmente, en la regulación del contrato de transporte marítimo de mercancías en general, el

el pasajero sufra daño alguno en su persona ni en su equipaje. El contrato gira así en torno a la obligación de transporte. Cfr. Quintana (1977) pp. 101 y ss.

17 En el derecho italiano, el transporte de cosa determinada, cuya ejecución es confiada a las naves de línea, se caracteriza, respecto del transporte de carga total o parcial, por la diversidad del objeto (paquete en vez de cargamento) y por la facultad del transportista para sustituir la nave designada. Esta facultad, reglada en el artículo 451 del Codice della Navigazione, permite reemplazar la nave utilizada, salvo prohibición expresa. Constituye de esta manera una opción del transportista de carácter genérico, diferente de aquella en que se permite la sustitución de la nave designada con otra indicada o a indicarse según su elección. Cfr. Lefebvre (2011) p. 463. El buque desempeña una función instrumental en el contrato, el objeto del contrato es el traslado de personas o bienes. Cfr. Manca (1970) p. 18. 
artículo 1600 del CCo. col establece como obligación del porteador marítimo proceder en el tiempo estipulado o usual, de manera apropiada y cuidadosa al "cargue, estiba, conservación, transporte, custodia y descargue de las cosas transportadas".

Sin duda alguna que en el caso colombiano, la unidad de regulación del contrato de transporte marítimo de mercancías en un solo instrumento jurídico (el Código de Comercio), así como su adopción por nuestro país en una fecha relativamente cercana en el tiempo (año 1971), hizo que no se presentasen los conflictos que surgieron por la vigencia simultánea de distintas regulaciones provenientes de distintas familias jurídicas y elaborados en épocas diferentes.

Debemos, sin embargo, interpretar la normativa del Código de Comercio colombiano en relación a la normativa internacional también vigente, en particular, las Reglas de La Haya-Visby, las Reglas de Hamburgo y las Reglas de Rotterdam, en cuanto a estas regulaciones se remiten los contratos y formularios que normalmente se utilizan en la práctica de la negociación internacional ${ }^{18}$. En estos casos, por tanto, el intérprete se verá en la obligación de dar efecto a esos pactos entendidos a la luz de nuestras instituciones jurídicas que pertenecen al ámbito continental europeo.

18 En los formularios contractuales, como no puede ser de otra manera, prevalece el contenido que las partes quieran establecer como regla de sus relaciones económicas de transporte marítimo de mercancías. Sin embargo, en la práctica, muchos de ellos se refieren a la normativa del Convenio de Bruselas de 1924 y a sus protocolos modificatorios de 1968 y 1979. En este sentido, por ejemplo, el formulario de conocimiento de embarque NEW ZEALAND SOUTHBOUND TRADE BILL OF LADING 1978 establece expresamente: " 1 . It is mutually agreed that this Bill of Lading shall have effect subject to the provisions of the International Convention relating to Bills of Lading dated Brussels 25th August, 1924 (hereinafter called the Hague Rules as amended by the Protocol signed at Brussels 23rd February, 1968 (hereinafter called the Hague Visby Rules) is compulsory applicable, in which this case this Bill of Lading shall have effect subject to the provisions of such legislation. Neither the Hague Rules nor the Hague Visby Rules shall apply to this Contract where the goods carried hereunder consist of live animals or cargo which by this contract is contained shall be deemed to be a surrender by the Carrier of any of his rights or immunities or an increase of any of his responsibilities or liabilities under the provisions of the said legislation or Rules (as the case may be) and the said provisions shall not (unless and to the extent that they are by law compulsory applicable) apply to that portion of the contract evidenced by this Bill of Lading which relates to forwarding under Clause 4 hereof, if anything herein contained be inconsistent with or repugnant to the said provisions, it shall, to the extent of such inconsistency or repugnance and no further, be null and void'. Igualmente en el formulario CONGENBILL 1978 de la Baltic and International Maritime Conference (BIMCO) se establece: "(2) General Paramount Clause. The Hague Rules contained in the International Convention for the Unification of certain rules relating to Bills of Lading, dated Brussels the $25^{\text {th }}$ August 1924 as enacted in the country of the shipment shall apply to this contract. When no such enactment is in force in the country of shipment, the corresponding legislation of the country of destination shall apply, but in respect of shipments to which no such enactments are compulsorily applicable, the terms of the said Convention shall apply. Trades where Hague-Visby Rules apply. In trades where the International Brussels Convention 1924 as amended by the Protocol signed at Brussels on February $23^{\text {rd }} 1968$-the Hague-Visby Rules-apply compulsorily, the provisions of the respective legislation shall be considered incorporated in this Bill of Lading. The carrier takes all reservations possible under such applicable legislation, relating to the period before loading and after discharging and while the goods are in the charge of another carrier, and to deck cargo and live animals". Igualmente existen también otros formularios contractuales que si bien no establecen expresamente como norma reguladora las Reglas de La Haya Visby, si incorporan una regulación similar a la establecida en esta normativa, como es el caso, por ejemplo, del formulario de conocimiento de embarque utilizado por la Línea Mexicana del Pacífico. 


\section{LA OBLIGACIÓN DE TRANSPORTE COMO FUNDAMENTAL DEL CONTRATO DE TRANSPORTE MARÍTIMO DE MERCANCÍAS EN EL DERECHO COMPARADO}

En el derecho francés, el legislador ha optado por regular el transporte marítimo de mercancías a través de una ley especial ${ }^{19}$. A pesar de que originariamente la Ordenanza Francesa de 1681 entendía al contrato de fletamento como un contrato de alquiler de buque. La regulación actual del transporte marítimo de mercancías lo considera un contrato de transporte, en cuyo centro está la obligación de traslado de las mercancías.

La ley que actualmente está en vigor es la 66-420 del 18 de junio de 1966, reguladora de la materia de fletamento y transporte de mercancías por mar. En el artículo 15 establece que por el contrato de transporte marítimo el cargador se compromete a pagar un flete determinado y el transportador a conducir o trasladar una mercancías determinada de un puerto a otro ${ }^{20}$. A esta referencia expresa debemos agregar que la mencionada ley (art. 21) reconoce en este tipo de contratos la existencia de otras prestaciones con un tratamiento jurídico especial.

A su vez el Código de Comercio chileno incorpora claramente la obligación de transporte al establecer, en su artículo 974, que "se entiende por contrato de transporte marítimo aquel en virtud del cual el porteador se obliga, contra el pago de un flete, a transportar mercancías por mar de un puerto a otro".

Por otro lado, en el derecho británico la institución reguladora del transporte marítimo de mercancías es el fletamento (affreightment) ${ }^{21}$, en virtud del cual un naviero, bien sea directamente o a través de un agente, se compromete a transportar mercancías por mar o a proveer un buque para tal propósito. La institución del fletamento se puede instrumentalizar a través de dos formas documentarias, bien sea utilizando una póliza de fletamento (charterparty), en la cual el fletante se compromete a poner a disposición del fletador la capacidad completa de su buque para un determinado viaje o por un específico período de tiempo, o bien se utiliza un conocimiento de embarque (bills of lading) si se emplea el buque en un servicio de línea, transportando con regularidad mercancías de diferentes cargadores $^{22}$. Entre estos dos supuestos, que como ya lo habíamos mencionado, corresponden

\footnotetext{
19 El hecho de que la regulación del transporte marítimo de mercancías en Francia se haya realizado a través de leyes especiales, en vez de reformas del Código de Comercio, o bien, mediante la promulgación de un código propio de legislación marítima (opción italiana), parece tener explicación en la discusión que dentro de la doctrina francesa se suscitó respecto a la independencia del derecho marítimo respecto del derecho privado. La idea del particularismo del derecho marítimo, expuesta inicialmente por G. Ripert y profundizada por Bonnecase, como solución que podríamos llamar intermedia, puede hacernos comprender esta opción. La regulación a través de una ley especial, por un lado permite a la norma jurídico-marítima, como norma particular que es, mantener formalmente una relativa independencia del derecho privado, aunque por otro se le niege una completa autonomía. Cfr. Arroyo (1985): p. 63.

20 Cfr. Art. 15: "Par le contrat de transport maritime, le chargeur s'engage à payer un fret déterminé et le transporteur à acheminer une marchandise déterminée, d'un port à un autre».

21 Cfr. Wilson (1993) pp. 3 y ss.; Cfr. Chorley (1992) p. 165 y ss.; Colinvaux (1982) pp. 37 y ss.; Mocatta et al. (1984) pp. 1 y ss.

22 Cfr. Chanda (2012) pp. 65-82.
} 
a situaciones económicas diferentes, el que verdaderamente nos interesa es el último, por cuanto es el equivalente al contrato de transporte marítimo, consagrado en la Ley española de Transporte Marítimo de 1949 y al contrato de transporte marítimo de mercancías bajo conocimiento de embarque regulado en el Código de Comercio colombiano. Al igual que ha ocurrido en el derecho continental, el contrato celebrado utilizando la forma de conocimiento de embarque, comprende dentro de su contenido una finalidad del transporte como elemento esencial del mismo.

Frente al particularismo de la doctrina francesa, el derecho italiano optó por la autonomía del derecho marítimo ${ }^{23}$. Con base en ella integró las normas reguladoras del transporte marítimo de mercancías en el Código de la Navegación, dentro de un ordenamiento jurídico regulador de las actividades de navegación marítima y aérea. De acuerdo con la normativa correspondiente al transporte marítimo de mercancías (entre ellos, los artículos 419, 439 y 451) por virtud del contrato de transporte, el transportista se obliga frente a otra persona, a transferir o trasladar de un lugar a otro una carga total o parcial o bien una cosa singular, en una nave determinada o bien indeterminada ${ }^{24}$. La obligación de traslado de un lugar a otro constituye la prestación fundamental que debe ser realizada por el porteador dentro de la ejecución del contrato.

Finalmente, es indispensable mencionar el tratamiento que las Reglas de Hamburgo de 1978 y las Reglas de Rotterdam de 2008 dan al punto que tratamos. Es evidente la importancia internacional de estos dos instrumentos jurídicos, en cuanto tienen vocación a regir la materia en el futuro, a pesar de que las primeras no han sido aún ratificadas por España y Colombia y, las segundas, no han entrado aún en vigencia. Ambas regulaciones también serían aplicables de manera inmediata cuando los particulares a ellas se remitan en uso del principio de autonomía privada.

La Convención de la Naciones Unidas sobre el Transporte Marítimo de Mercancías, celebrada en Hamburgo en 1978, se ha pronunciado reconociendo, en el artículo 1, apartado 6, que por este tipo de contratos el porteador se compromete, contra el pago de un flete, a transportar mercancías por mar de un puerto a otro.

De la misma forma, el artículo 1 de las Reglas de Rotterdam, define "contrato de transporte" como aquel contrato en virtud del cual el porteador se compromete, a cambio del pago de un flete, a transportar mercancías de lugar a otro y, el artículo 11 establece que "con arreglo al presente Convenio, y de conformidad con lo estipulado en el contrato de transporte, el porteador deberá transportar las mercancías hasta el lugar de destino y entregarlas al destinatario" 25 . Evidente es la referencia a la obligación de transporte como esencial dentro de la estructura del contrato de transporte marítimo de mercancías en ambos convenios.

\footnotetext{
23 La estructura del Codice della Navigazione Marittima e Aerea, como código autónomo de la legislación común, tuvo su origen en las tesis de A. Scialoja, quien enunció la necesidad de una separación del derecho marítimo respecto a las normas de derecho privado, sobre la base de que las normas reguladoras de materias marítimas tienen un común denominador, la navegación, que les da unas características propias. Cfr. RiGHETTI (1987) pp. 1390 y ss.; Arroyo (1985) p. 63.

24 Cfr. Lefebvre y Pescatore (2011) p. 463; Manca (1970) p. 18; Costa (1986) pp. 883 y ss.

25 Cfr. Sáenz García (2010) pp. 111-137; Berlingieri (2012) pp. 53-100.
} 


\section{LA REALIZACIÓN DEL TRANSPORTE COMO OBLIGACIÓN COMPLEJA}

Sin perjuicio de que nuestra opinión se oriente, por las razones antes expuestas, a la consideración de una única obligación de transporte, la práctica del derecho vigente nos lleva a entender la ejecución de un contrato de transporte marítimo de mercancías basado en distintos deberes, que se entrecruzan entre sí, para obtener un determinado resultado económico. No podemos negar el hecho real de que la regulación vigente tanto en España como en Colombia, divide el aspecto positivo del contrato en diversos deberes con contenidos particulares ${ }^{26}$. Por lo tanto, en la medida que nuestro análisis debe orientarse al derecho actualmente vigente, no podemos eludir esta situación debiendo trabajar sobre una estructura plural de deberes, respetando el contenido que le ha sido dado tanto a nivel legislativo como jurisprudencial.

Ahora bien, si el traslado de las mercancías por el porteador al destino pactado, constituye la obligación esencial del contrato de transporte marítimo de mercancías, las conductas que este debe realizar no se agotan allí en el mero traslado, sino que existen otros comportamientos que deben realizarse a fin de alcanzar el propósito deseado por las partes. El problema que ahora se nos presenta es cómo podemos integrar estas otras conductas, reconocidas y reguladas expresamente por la normativa legal. Por un lado podemos optar por otorgarles una categoría de obligaciones autónomas, de tal forma que el contenido contractual esté constituido por un conjunto de obligaciones independientes, ante cuyo incumplimiento, la parte afectada pueda exigir las consecuencias previstas jurídicamente sin tomar en consideración las otras obligaciones. Por otro tenemos la alternativa de considerar el contrato como un todo complejo en el que ambas partes, aunque con prestaciones contrapuestas, tienen un objetivo económico común. Esta última perspectiva nos obliga a entender las distintas prestaciones que nacen del contrato como partes integrantes de un todo y por lo tanto no necesariamente independientes ${ }^{27}$.

Concretándonos al tema estudiado, paralelamente a la existencia de una obligación fundamental de transporte de mercancías, existen otras conductas exigibles, que debemos entender íntimamente vinculadas entre ellas frente a un proyecto con contenido económico acordado por las partes. Así, para el cabal cumplimiento de la obligación principal, el porteador debe realizar varias prestaciones, que si bien hacen parte del concepto general transporte, llegan a adquirir relevancia en la medida en que el legislador les ha señalado un

\footnotetext{
26 La adopción del sistema de obligaciones que supone el Convenio de Bruselas de 1924, significa actualmente optar por favorecer los intereses del porteador, por encima de los del cargador. Una estructura basada en una división de obligaciones, con un alcance y contenido especial es el soporte de un régimen de responsabilidad del porteador igualmente especial, que en términos generales podríamos afirmar favorecen los intereses porteadores.

${ }_{27}$ El concepto de relación jurídico obligatoria puede sernos de utilidad para entender este planteamiento. Sobre este tema puede verse a DíEz-PICAZO, quien distingue esta relación del concepto más restringido de obligación. Es relación jurídica aquella establecida entre dos o más personas y dirigida a que una de ellas obtenga determinados bienes o servicios mediante la cooperación de la otra o mediante el intercambio recíproco de bienes y servicios. Por el contrario, la obligación se refiere a la simple correlación que existe entre un derecho de crédito y un deber jurídico a partir de la existencia de un vínculo jurídico. También Mapelli estructura las obligaciones que surgen del contrato de transporte siguiendo el concepto de relación obligatoria. Cfr. Dí́zZ-PicAzo (1993) p. 127; MAPELLi (1987) p. 66.
} 
contenido especial que las enriquece ampliando el contenido obligacional en esta clase de contratos. Es decir nos encontramos frente a una relación obligatoria, entendida como una situación jurídica compleja a través de la cual las partes (porteador y cargador) realizan el cumplimiento de unas prestaciones para alcanzar unas determinadas finalidades socioeconómicas ${ }^{28}$.

La relación jurídico obligatoria que surge en virtud del contrato comprendería por tanto todos los deberes, derechos, titularidades y cargas jurídicamente reconocidos y necesarios para la realización de los objetivos propuestos. Concretamente en el contrato de transporte marítimo de mercancías comprende todas las prestaciones necesarias para el cumplimiento de la obligación especial de transporte ${ }^{29}$ enunciadas en el caso de la legislación española, en los artículos 5 de la Ley de Transporte Marítimo de Mercancías de 1949 y 3 del Convenio de Bruselas de 1924 que a continuación examinamos. En el caso de la legislación colombiana en los artículos 2070 y siguientes del Código Civil Colombiano, 981 y siguientes del Código de Comercio colombiano.

Dentro de los deberes que surgen por la formación de un contrato de transporte marítimo de mercancías debemos destacar el denominado deber de custodia y conservación de las mercancías transportadas y el deber de entrega de las mercancías en el puerto de destino. Tradicionalmente el derecho marítimo también ha regulado la denominada obligación de navegabilidad del buque, cuyo estudio, por haberlo realizado en estudios anteriores ${ }^{30}$, nos abstenemos de reproducir en este texto, teniendo además presente las limitaciones de espacio que una revista científica exige.

\footnotetext{
${ }^{28}$ La jurisprudencia española del Tribunal Supremo no ha elaborado una sistematización de las prestaciones que integran el contrato de transporte marítimo de mercancías entendidas como un todo complejo constitutivo de una sola relación obligatoria. En las decisiones en las cuales ha asumido el tema se ha preocupado más por delimitar la obligación de transporte de las obligaciones de carga y descarga de la mercancía, entendidas como operaciones reguladas por contratos autónomos del contrato de transporte, normalmente realizadas por empresas independientes de aquella que realiza el transporte. Así por ejemplo en la sentencia del Tribunal Supremo del 31 de enero de 1983 refiriéndose a las operaciones de carga y de descarga de la mercancía, expresó lo siguiente: " 3) ... con todo, no puede desconocerse que también, toda esa serie de operaciones preliminares y finales que preparan o ponen término al desplazamiento marítimo e inicial al terrestre (depósito, almacenaje, manutención, peso, separación, clasificación, despacho, desplazamientos dentro del área portuaria, etc.), los accidentes que los caracterizan, el ritmo que el moderno tráfico marítimo les exige, la administración de los servicios de carga y descarga, ... desembocan a veces en el alumbramiento de una causa verdaderamente autónoma respecto del transporte marítimo cuanto más del transporte terrestre que le sigue o no, debiendo registrarse la existencia de empresas independientes de las de transporte y específicamente dedicadas al objeto de la carga y descarga, designadas por el porteador o por el cargador o receptor, casos estos en que el contrato adquiere un relieve incuestionable desprendiéndose limpiamente de los de transporte, no debiendo descartarse tampoco la posibilidad de mantener la misma autonomía del contrato de carga y descarga aun siendo partes las mismas que en el transporte marítimo ..., quedando configurado este contrato de carga o descarga como un contrato singular perteneciente al amplio género de la "locatio operis" y formando dentro del mismo una modalidad, atípica por ahora, integrada por prestaciones de naturaleza no solo variable sino también heterogénea y aún propia de otras figuras jurídicas...". ArANZADI Jur. nro. 401. También en: ArRoYo (1989) pp. 1181-1188.

29 Algunos como el Prof. Broseta Pont les dan el carácter de obligaciones accesorias o instrumentales que surgen de la naturaleza del contrato y del medio del transporte utilizado. Cfr. BRosetA (1994) p. 839.

${ }^{30}$ Cfr. Jiménez Valderrama (1999) pp. 165-185.
} 


\section{EN PARTICULAR: EL DEBER DE CUSTODIA Y CONSERVACIÓN DE LAS MERCANCÍAS TRANSPORTADAS}

El artículo 3.2 del Convenio de Bruselas establece, entre otras obligaciones del porteador, la de proceder de manera apropiada y cuidadosa a la custodia y conservación de las mercancías transportadas. El conservar y custodiar las cosas objeto del contrato es fundamental y consustancial al hecho mismo del transporte que por definición implica el traslado de mercancías de un lugar a otro en las mismas condiciones en que han sido entregadas por el cargador ${ }^{31}$.

La existencia de esta obligación, así como la obligación de entrega de la mercancía una vez transportada, tiene su base en la misma idea que fundamentó en el derecho romano la responsabilidad ex-recepto, por la cual debe restituirse la cosa entregada en las mismas condiciones en que fue recibida, surgiendo por tanto un deber de custodia y conservación ${ }^{32}$.

Desde este punto de vista, tal como lo afirma la doctrina inglesa ${ }^{33}$, la posición que asume el porteador es la misma que la de un depositario ordinario (common bailee). Gráficamente el buque correspondería a un almacén y el porteador (shipowner) a un depositario, surgiendo para este el deber de asumir un cuidado razonable de los bienes ${ }^{34}$. En el Common Law el depósito que asume el porteador exige por su parte un especial cuidado. La naturaleza misma de la obligación de transporte como de resultado establece que por el hecho de la entrega inicial de la mercancía el riesgo por la pérdida o avería de la misma lo asume el porteador salvo

\footnotetext{
31 Paralelamente, en el contrato de transporte de personas existe una obligación a cargo del transportista, consistente en transportar al pasajero sano y salvo a su destino (obligación de seguridad). Cfr. QuinTANA (1977) p. 107. El Código de Comercio colombiano establece expresamente, en el transporte de personas, la obligación de conducirlas sanas y salvas al lugar de destino (Art. 982 CCo. colombiano), así como, en el transporte de enfermos, dementes, menores de edad, a prestar "los cuidados ordinarios que exija su estado o condición" debiendo responder "por falta de esos cuidados y, en todo caso de los que ocasionen estas personas a los demás pasajeros o cosas transportadas...” (artículo 1005 CCo. colombiano).

32 "El transportista es responsable de las pérdidas y averías, cualquiera que sea su origen, si se prueba que ocurrieron por su negligencia o por falta de adopción de las precauciones usuales en la custodia de lo transportado (art. 362 del Código de Comercio)... 2) Que la falta parcial de la mercancía porteada por la empresa se deriva de hechos ejecutados a bordo del barco en que se transportaba el vehículo, la demostración de que al conductor o responsable del mismo no le era lícito ni posible custodiar la carga del mismo mientras permaneciese a bordo, es al mismo tiempo la demostración por vía indirecta, de que no hubo negligencia por su parte, ...”. Sentencia de la Audiencia Provincial de Santa Cruz de Tenerife, 8 de septiembre de 1982. Tomado de Sentencias de las Audiencias Territoriales, en Anuario de Derecho Marítimo, Vol. III, pág. 959.

33 Cfr. Chorley (1992) p. 186. Por otro lado, alguna parte de la doctrina española también asimila la obligación de custodia y conservación de la mercancía a la situación que tiene un depositario. Cfr. Hernández (1984) p. 95.

34 La jurisprudencia italiana en diversas sentencias ha considerado la obligación de custodia como un vínculo del porteador de carácter continuado: Corte d'Appello di Napoli, 29 de marzo de 1968, causa Ditta Luigi Pittaluga c. Sorveglianza (Il Diritto Marittimo, 1968, p. 395): "La obligación del transportista no se agota con el aprestamiento de la nave y de la estiba, el propietario debe mantener una continua y prudente (cuidadosa) vigilancia de la carga por toda la duración del transporte". En el mismo sentido Sentencia de la Corte d'Appello di Genova, 26 de noviembre de 1969, caso Montedison c. Cima (Il Diritto Marittimo, 1970, p. 148); por otro lado, esta última decisión aclara que dentro de la obligación de custodia se integra todo aquello necesario para que no llegue deteriorada al destino la mercancía, incluyendo la noción técnica para conseguir tal resultado. Cfr. BERLINGIERI (1978) pp. 53 y ss.
} 
casos excepcionales constitutivos de caso fortuito o fuerza mayor ${ }^{35}$, y aquellos eventos conocidos doctrinalmente como peligros exceptuados propios del derecho anglosajón.

En el caso del Código de Comercio colombiano, el artículo 1600, cuando regula el transporte marítimo de carga general, establece como obligación del transportador proceder en el tiempo estipulado o usual, de manera apropiada y cuidadosa al "cargue, estiba, conservación, transporte, custodia y descargue de las cosas transportadas".

La obligación de custodia y conservación de las mercancías transportadas no debe realizarse indefinidamente, sino que tiene una limitación temporal claramente definida: debe prestarse a partir de la recepción de la mercancía por el porteador y se extiende hasta su entrega al destinatario o consignatario. En el caso del derecho colombiano, el artículo 1604 del Código de comercio establece como periodo de responsabilidad del transportador marítimo desde su recepción hasta su entrega al destinatario, presumiéndose recibido en la fecha de emisión del documento de transporte. Por otro lado, el artículo 1030 de la normativa codificada establece que la responsabilidad del transportador cesará transcurridos 5 días después del día fijado para su entrega o aviso de la misma, si no ha sido retirada por el interesado, teniendo el transportador derecho a que se le pague el bodegaje acostumbrado en la plaza.

Los actos de recepción y entrega de las mercancías no deben confundirse con los de carga y descarga de la misma. Como lo afirma Sánchez Calero ${ }^{36}$ la carga y descarga son operaciones instrumentales referentes a un resultado que el porteador está obligado a prestar: la entrega de la mercancía. La obligación de entrega de la mercancía, recae siempre sobre el mismo porteador. La descarga como operación instrumental puede o no ser realizada por el mismo porteador, e incluso, por pacto expreso, puede corresponder al destinatario o al consignatario de la mercancía.

En general las faltas de este deber constituyen faltas comerciales del porteador y por lo tanto dan lugar a la indemnización por concepto de las pérdidas o los daños causados. Como pertenecientes a tal categoría no pueden ser objeto de exoneración por los actos cometidos por los dependientes, como sucede con las faltas náuticas.

Jurisprudencialmente se reconoció su carácter de falta comercial en sentencia del Tribunal Supremo español de fecha 29 de enero de $1985^{37}$. Se discutía el derecho de indemnización de un cargador por un eventual incumplimiento de la obligación de custodia y conservación por parte del porteador. Un buque había hecho escala en el puerto de Barcelona

35 Dentro de la Jurisprudencia española, en este sentido ver Sentencia del Tribunal Supremo, 1 de junio de 1966, Aranzadi Jur. nro. 2845. Tambien en Arroyo (1989) p. 887.

36 Cfr. Sánchez Calero (1957) p. 65.

37 El texto pertinente de la sentencia es el siguiente (considerando tercero): “ ... al proceder los daños y faltas de un comportamiento derivado de faltas de relación con el manejo, cuidado y custodia del cargamento, concretamente causado por el transporte de los vehículos en cuestión en zonas de sobrecubierta y entreplanta, motivador de que en puerto de tránsito de Barcelona se hubiese precisado descargarlos, en parte, y de que en tal ocasión uno de los vehículos, en el momento en que estaba suspendido por grúa o penetal cayó sobre otros de la propia partida, con la producción de los consiguientes daños, y cuyos daños y faltas, por su consecuencia, determinaría responsabilidad civilmente del porteador de conformidad con lo convenio en el artículo 6 de la invocada Ley de 22 de dic. de 1949 y al no darse ninguna de las causas de exoneración comprendidas en los artículos 8 y 9 a que el referido 6 se remite”. Cfr. Tribunal Supremo, 29 de enero de 1985, Aranzadi Jurisprudencia nro. 807. También en Arroyo (1989) pp. 1243-1249. 
para cargar mercancías, sin embargo para realizar esta operación, fue necesario descargar varios vehículos que estaba transportando y que habían sido cargados en puertos anteriores. En la realización de esta operación uno de los vehículos se soltó cayendo sobre otros y ocasionando diversos daños.

El Tribunal consideró que el porteador de las mercancías era responsable de los daños ocasionados por cuanto había cometido faltas en relación con el manejo, cuidado y custodia de las mismas ya que había transportado los vehículos en zonas de sobrecubierta y entreplanta, hecho que motivó su descarga en el puerto de Barcelona para poder realizar la carga de otras mercancías.

\section{EN PARTICULAR: EL DEBER DE ENTREGA DE LA MERCANCÍA}

Una vez realizado el traslado de la mercancía, el porteador debe entregarla a su destinatario, esto es, debe realizar los actos necesarios para que el destinatario adquiera la posesión de las mercancías transportadas ${ }^{38}$. La realización de esta obligación tiene particular

38 La doctrina civilista ha discutido ampliamente sobre la naturaleza jurídica y el contenido de la entrega. El dilucidar ambos aspectos han surgido algunas dificultades, especialmente por la estrecha vinculación que tradicionalmente se ha asignado al concepto de entrega o tradición con el cumplimiento de las obligaciones de dar, generando de esta manera alguna confusión conceptual, por cuanto que se identifica a la entrega o tradición como evento siempre productor de efectos traslaticios de dominio. Por su parte, la mayor parte de la doctrina actual, distingue el carácter meramente instrumental de la entrega, autónoma de los efectos diversos que su realización pueda originar, que dependen de la relación contractual dentro de la cual esta se produzca (arrendamiento, depósito, compraventa, transporte). Desde esta perspectiva se ha entendido que la entrega tiene en primer lugar un carácter obligacional, cuyo contenido está definido por la transmisión voluntaria de la posesión por parte del que actualmente la ejerce (tradens) a quien comenzará a ejercerla (accipiens). Se trata por lo tanto, de una obligación de hacer (Rubio Garrido), en virtud de la cual el deudor debe realizar todos aquellos actos y operaciones necesarios para que el acreedor asuma la posesión del bien objeto de la entrega. Desde la óptica del Contrato de Transporte Marítimo de Mercancías, se definiría como la obligación del porteador, quien ya ha realizado el transporte, para poner en posesión de la mercancía al destinatario de la misma, esto es quien esté legitimado para reclamar su restitución, de acuerdo con el texto del conocimiento de embarque o del contrato de transporte marítimo correspondiente. La idea de la entrega o tradición de la mercancía como una transmisión derivativa de la posesión, aplicada al contrato de transporte, ha encontrado algunas reticencias doctrinales principalmente por la intervención en este tipo de contratos de documentos que como el conocimiento de embarque asignan a su titular la posesión sobre los bienes que están siendo transportados, con la finalidad de facilitar su negociación in transitu. El tenedor del conocimiento ya es poseedor de la mercancía, por lo tanto, en la entrega mal podría hablarse de una transmisión de la posesión a alguien que ya tiene la categoría de poseedor. Por ello, respecto a este tipo de contratos, se ha distinguido doctrinalmente entre los conceptos de posesión, y tenencia de la mercancía (Goldschmidt), y dentro del concepto de posesión entre posesión mediata e inmediata (Recalde Castells). De esta manera, la entrega del conocimiento de embarque implica la transmisión de la posesión mediata sobre la mercancía (que se concreta en el derecho que tiene su legítimo tenedor para obtener la restitución de las mercancías transportadas), evento diferente a la entrega de la mercancía en puerto de destino por el porteador que conlleva la transmisión de la posesión inmediata de la mercancía (Recalde Castells) o la tenencia de la misma (Sánchez Calero) que puede realizarse mediante el traspaso real de la mercancía (poner en poder y posesión, art. 1462 del C. C. español) o por los medios reconocidos legalmente como equivalentes a dicha entrega (poner a disposición, art. 333 del C. de Co. español). Cfr. Díez-PiCazo (1995) p. 240. También en Díez-Picazo (1966) pp. 555 y ss; Albaladejo (1994) pp. 146 y ss.; Lacruz Berdejo et al. (1990) p. 227; Rubio Garrido (1993) p. 149; Recalde Castells (1992) p. 47; Sánchez Calero (1957) p. 64. Respecto a la naturaleza obligacional de la entrega también puede verse: DANJON (1934) p. 397; Hernández Martí considera la entrega de la mercancía como una prestación que desencadena una serie de efectos jurídicos, los cuales para 
interés por cuanto su realización supone el cumplimiento de la obligación de transporte de las mercancías ${ }^{39}$.

Bien se trate de una obligación autónoma o de la ejecución de una obligación de transporte actualmente existente, el acto de entrega de la mercancía tiene una importancia fundamental en este contrato por cuanto pone fin a la relación jurídico obligatoria de transporte, liberando al porteador de las prestaciones que nacen de la misma y por otro lado, marca el momento temporal que divide la traslación de los riesgos desde el porteador hacia el destinatario, pudiendo ser este último el mismo cargador, su representante o consignatario o un tercero actualmente titular del conocimiento de embarque en virtud de válida transmisión.

Correlativamente al deber de entrega de la mercancía, existe por parte del destinatario una carga de retirarla, a fin de colaborar en la solución de la obligación de transporte por parte del porteador. Es decir, el destinatario tiene radicado en su cabeza una carga de facilitación de la liberación del deudor, que aunque no exigible coactivamente puede su inobservancia acarrearle consecuencias gravosas como colocarle en situación de mora de recibir, posibilitando al porteador la facultad para utilizar los medios legales establecidos para obtener su liberación ${ }^{40}$.

La entrega de la mercancía no debe confundirse con la operación de descarga de la misma. Aunque ambos actos pueden coincidir temporalmente, puede que no suceder así. La entrega de la mercancía puede producirse bien a bordo del buque, caso en el cual las operaciones y gastos de descarga corresponderían al destinatario, por ejemplo en las cláusulas "F.I.O." (Free in and out), "Quai à bord" y "Bascule sur le pont"; o bien al costado del buque, cuando a través de los aparejos del mismo buque se dejan las mercancías sobre el muelle, mediante las cláusulas "Along side", "From the ship’s tackle", o "Sous palan" ${ }^{41}$ Igualmente, la entrega puede realizarse en almacenes del porteador o de una tercera persona, casos en los que el momento de la entrega es posterior al de la realización de la descarga.

el caso concreto que estamos examinando son de carácter extintivos de la obligación de transporte. Cfr. HerNÁNDEZ MARTí (1984) p. 95.

39 El Tribunal Supremo español se ha pronunciado en repetidas ocasiones en materia de la entrega en el contrato de transporte marítimo de mercancías. En general se admite el carácter obligacional de la entrega. Cfr. Sentencias del 17 abril 1889 (Tomado de Arroyo (1989) p. 59-61): “ 2) Por el contrato de fletamento se obliga a entregar el cargamento en puerto designado por el fletador, siendo directamente responsable si así no lo verifica sin causa legítima”; del 2 julio 1889 (Tomado de Arroyo (1989) pp. 62-63): “2) En el contrato de transporte marítimo, debe cumplirse la obligación en el lugar en que, según el conocimiento de embarque, debe efectuarse la entrega de las mercancías"; y del 1 de Junio de 1966. En la Jurisprudencia inglesa puede verse: Brandt $v$. Liverpool, Brazil and River Plate Steam Navigation C. Ltd. [1923] All E. R. Rep. 656. Tomado de Ivamy (1989) pp. 87-88: "Atkin, L.J. (pag. 664): I have no doubt at all that the obligation on the shipowner is an obligation to deliver on the terms of the bill of lading. I think it follows that the implied contract that arises in cases such as this is that the holder of the bill of lading and the shipowner make a contract for the delivery and acceptance of the goods on the terms of the bill of lading...”.

40 Cfr. DíEz-Picazo (1995) p. 111.

41 La inclusión de estos acuerdos (también de las cláusulas FIOS, FIOST, FILO o LIFO) en los documentos contractuales que rigen el transporte marítimo, alteran el reparto de deberes y costos, asignándolos a personas distintas del porteador marítimo, como puede ser el destinatario de la mercancía. En este caso atendiendo al reconocimiento de la autonomía privada, las partes establecen las condiciones específicas que regulan sus relaciones de transporte. 
Para que la entrega sea liberatoria de las obligaciones asumidas por el porteador en el contrato, debe recaer sobre las mismas mercancías recibidas por el porteador, que deben ser devueltas en las mismas condiciones. El acto de entrega debe realizarse a aquella persona quien en virtud del conocimiento de embarque esté el legitimado como titular del derecho $^{42}$. Por otro lado, el hecho de entrega debe realizarse dentro del plazo pactado por las partes.

En cuanto a los gastos que se generen por la entrega de las mercancías objeto de transporte son por regla general de cuenta de la empresa porteadora ${ }^{43}$, salvo que por pacto expreso se establezca lo contrario.

En sentencia del 28 de junio de 1943, el Tribunal Supremo español decide un caso en el cual se había firmado una póliza de fletamento entre dos empresas para el transporte de mercancías. Esta decisión atrae nuestro interés en la medida que luego de examinar el valor de la documentación emitida por causa de la celebración de un contrato de fletamento, afirma que el conocimiento de embarque como documento de transporte revela una recepción (receptum) de la mercancía, y es en este hecho reconocido legalmente que tiene su base la posterior obligación de entrega de la mercancía ${ }^{44}$.

En el derecho colombiano el Código Civil en el artículo 2073 establece que "el acarreador es obligado a la entrega de la cosa en el paraje y tiempo estipulados...". Los artículos 982 y 1008, esta vez del Código de Comercio colombiano también mencionan expresamente esta obligación para el transportador ${ }^{45}$.

42 Es claro que la obligación de entrega de las mercancías debe ejecutarse en el lugar que especifique el conocimiento de embarque. Cfr. Sentencia del Tribunal Supremo, 26 de noviembre de 1909, Col. Leg. núm. 70, pág. 483. Tomado de Arroyo (1989) p. 129.

43 En aplicación de la regla establecida en el artículo 1168 del Código Civil español, según la cual los gastos extrajudiciales que ocasione el pago son de cuenta del deudor. En el caso del derecho colombiano en virtud del artículo 1629 del Código Civil los gastos del pago corresponden al deudor.

44 En el considerando Primero el Tribunal Supremo afirma: "Que no obstante el puesto preeminente que ha adquirido en el tráfico moderno el conocimiento de embarque, hasta el punto de que corrientemente absorbe el contenido propio de la póliza de fletamento, es lo cierto que en nuestro ordenamiento jurídico normal de fletamento-transporte coexisten ambos documentos con una dirección o tendencia común a la realización del transporte, pero con finalidad específica distinta, pues mientras la póliza es expresión típica del contrato de fletamento y de sus condiciones, el conocimiento revela meramente el "receptum" de la mercancía y consiguiente obligación de entregarla en el punto de destino...”. Cfr. Tribunal Supremo, 28 de junio de 1943, Aranzadi Jur. nro. 843, tomado de Arroyo (1989) p. 472.

45 En este sentido también se ha pronunciado la Corte Suprema de Justicia de Colombia: "De conformidad con lo que dispone el artículo 981 del Código de Comercio, modificado por el artículo $1^{\circ}$ del decreto 01 de 1990, el transporte mercantil es un contrato por virtud del cual una de las partes, llamada transportador, transportista o porteador, se obliga con la otra, a cambio de un precio denominado flete o porte, a conducir de un lugar a otro, por el medio determinado y en el plazo fijado, personas o cosas y entregar estas al destinatario. Tratándose del transporte de cosas, asumen la calidad de partes, de un lado, el remitente, que es la persona que se obliga, por cuenta propia o ajena, a entregar las cosas que deben ser acarreadas, en las condiciones, lugar y tiempo convenidos, y del otro, el transportador, que es quien se compromete a recibir, conducir y entregar los objetos materia del convenio -artículo 1008 ibídem-. El destinatario, que puede ser el mismo remitente, o una persona diferente, es aquel a quien se envían las cosas transportadas y a quien deben entregarse en el lugar de destino. En los términos del citado texto legal, asume el rol de parte, “... cuando acepte el respectivo contrato”. El remitente, porteador o cargador, como también se le llama, y según se dijo, es la persona que se compromete a entregar al transportador los efectos materia del contrato, para su traslado desde el sitio de origen, hasta el lu- 
En materia de transporte de mercancías la normativa codificada colombiana integra una serie de compromisos específicos referidos a la obligación de entrega. De esta manera el transportador está obligado a avisar al destinatario de la llegada de la mercancía y el día y lugar de realización de la entrega (art. 1026 C. Co. colombiano), a falta de lo cual se entenderá deberá entregar en las oficinas y bodegas que el transportador determine. En el caso de que no se pueda entregar en el lugar y fecha convenida deberá avisar al destinatario sobre el momento y el lugar en el cual efectuará la entrega de la mercancía.

Según el artículo 1028 del Código de Comercio colombiano, recibida la cosa por el destinatario "sin observaciones", se presumirá cumplido el contrato, debiendo el receptor formular cualquier observación "en el acto de entrega y recibo de la cosa transportada" en caso de pérdida parcial, saqueo o avería, notorios o apreciables a simple vista. En caso de que por circunstancias especiales impidan el inmediato reconocimiento al momento de la entrega, podrá el destinatario recibirla bajo la condición de que se haga su reconocimiento, que deberá realizarse en los 3 días siguientes a la entrega con presencia del transportador o la persona por él designada.

En el caso de discrepancias sobre el destinatario o sobre las condiciones de entrega o si este no recibe, el transportador podrá depositar las mercancías o tomar cualquier medida "precautelativa" a costa del destinatario. Igualmente podrá disponer de las cosas fungibles o susceptibles de daño con licencia de la autoridad policiva del lugar, debiendo dar aviso “oportuno y detallado” al remitente (artículo 1029 del Código de Comercio colombiano).

gar de destino. Es entonces quien realiza el encargo, gestión en la cual puede obrar, como lo indica el texto legal antes citado, por cuenta propia o ajena. Actúa por cuenta propia, cuando encomienda el transporte en su propio beneficio, evento en el cual es indiferente que sea propietario o no de las cosas objeto de él, pues al efecto basta que tenga disponibilidad material sobre ellas. Obra por cuenta ajena, por el contrario, cuando lo contrata, no en su propio beneficio, sino en el de un tercero, para quien actúa, persona que es la real interesada en el contrato y la llamada a recibir sus efectos, vale decir, la afectación patrimonial derivada de él. En tal cometido, el remitente puede actuar, v. gr., como mandatario, comisionista de transporte, es decir, mandatario especializado en la contratación del servicio de transporte para terceros y con terceros, actuando en su propio nombre, agente oficioso, etc. El transportador, por su parte, queda principalmente obligado a la traslación de las personas o cosas objeto del contrato, desde el lugar de origen, hasta el sitio de destino, desplazamiento en el cual estriba el objetivo del citado pacto y puede llevarse a cabo de manera directa por el transportador, o encargarse, en todo o en parte, a un tercero, bajo la responsabilidad de aquel, sin que por ello varíen los términos del contrato, pues así se lo permite el art. 984 ejúsdem. En tal hipótesis, el transportador celebra con un tercero, en su propio nombre y por su cuenta, otro contrato de transporte, con el fin de ejecutar la operación de transporte a la cual se obligó, es decir para atender los compromisos que como transportista asumió en el contrato inicial”. Corte Suprema de Justicia de Colombia, Sala de Casación Civil, 30 de noviembre de 2004, Mag. Ponente: Jaime Alberto Arrubla Paucar, Consideración Primera. También en la Sentencia de la Corte Suprema de Justicia de fecha 8 de septiembre de 2011, Mag. Ponente: William Namén Vargas: “4. En virtud del transporte, el transportador, transportista o porteador contrae con el pasajero, remitente, cargador o porteador, la obligación de conducir de un lugar a otro, personas sanas y salvas o, la de recibir, conducir y entregar al destinatario cosas en el estado recibido, por el medio y en el plazo estipulados o, en su defecto, por vía razonablemente directa, en un término prudencial, según los horarios, itinerarios y normas establecidas en los reglamentos oficiales, a cambio de una contraprestación económica, precio, flete o porte (artículos 981, 982 y 1008, Código de Comercio; cas.civ. sentencia de 30 de noviembre de 2004, exp. 0324)". 


\section{SISTEMA DE OBLIGACIONES EN LAS REGLAS DE HAMBURGO DE 1978}

\section{A) Circunstancias económicas y políticas que rodearon la celebración de la Convención de Naciones Unidas sobre Transporte Marítimo de Mercancías (Hamburgo, 1978)}

Las condiciones que rodeaban la actividad naviera en 1924, año de la firma del Convenio de Bruselas, eran substancialmente diferentes a las que se presentaron 50 años después en los años previos a la firma del texto de Hamburgo. A partir del año 1950 se presenta un fuerte incremento de la capacidad de carga de las flotas de transporte a nivel mundial ${ }^{46}$. Dentro de la actividad económica de transporte de mercancías por mar el sector que mayor impulso tuvo fue el de hidrocarburos, determinado principalmente por las crecientes demandas de productos derivados del petróleo por parte de economías en proceso de industrialización.

Este aumento de la capacidad de carga no solamente se manifestó como consecuencia de un incremento en el número de buques transportadores, sino también por el aumento en el tonelaje de los mismos. El desarrollo de nuevas técnicas en la construcción de buques a la vez que posibilita naves con mayor capacidad, ofreció una mayor rapidez en el transporte debida principalmente a la utilización del motor diésel al que posteriormente se agregaron otros medios de propulsión como la turbina a vapor ${ }^{47}$. Es por ello que la navegación durante ese momento histórico se caracterizó por su rapidez y ante todo por una mayor seguridad frente a la navegación que se realizaba a principios del siglo XX.

Por otro lado, debemos resaltar la importancia que la tecnología en las comunicaciones ha adquirido a lo largo del siglo XX. Al momento de la elaboración de las Reglas de Hamburgo ya era posible la utilización de sofisticados medios de comunicación, dentro de ellos los que incorporaban el satélite como medio de interconexión, el cual permitía no solamente la comunicación del buque en alta mar, sino además le facilitaba el conocimiento de su ubicación exacta y las posibles eventualidades climáticas a las que tiene que hacer frente en el desarrollo de su travesía.

Simultáneamente al desarrollo en las técnicas de navegación y de construcción de buques, se presentaban en el ámbito económico una ampliación en la actividad de transporte de mercancías por mar, que sufrió una disminución importante en los años anteriores a la firma de las Reglas de Hamburgo. La crisis económica que se presentó a nivel mundial entre los años de 1974 y 1976 generó un fenómeno de sobrecapacidad en las flotas mercantes mundiales causando una recesión en el sector de transporte marítimo de mercancías.

Desde el punto de vista político, el período que se inició con la finalización de la segunda guerra mundial se caracterizó por la cada vez mayor intervención de los países en vías de desarrollo en las distintas decisiones políticas que se toman a nivel mundial. El pro-

\footnotetext{
46 Auchterd (1979) p. 12.

47 Hacia finales de los setenta, las dos formas de propulsión principalmente utilizadas eran el motor diésel y la turbina a vapor. Aproximadamente un $68 \%$ de las naves utilizaban la primera de estas alternativas, frente a un $32 \%$ que usaban la turbina a vapor, especialmente en naves de 100.000 toneladas o más. Cfr. Auchter (1979) p. 12; Gómez Segade (1980) p. 227.
} 
ceso de inserción de estos países se realizó a través de distintos organismos internacionales que se convirtieron en voceros de sus demandas y de sus intereses. Particularmente en el sector del transporte marítimo será de especial importancia este fenómeno en cuanto la Convención de Hamburgo fue convocada por iniciativa de la UNCITRAL, organismo de las Naciones Unidas especialmente sensible a los intereses de los países en vías de desarrollo.

Todo el ambiente económico y político que rodeó la creación de las Reglas de Hamburgo fue realmente determinante al momento de la adopción de las distintas directrices que plasma el texto de las Reglas de Hamburgo, como podremos constatar a continuación.

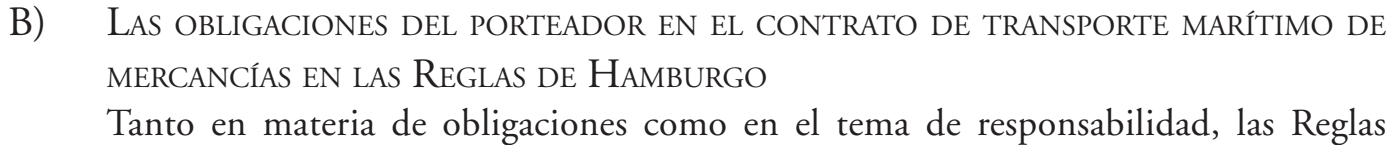
de Hamburgo constituyen una ruptura con el tratamiento que a estos temas había dado el Convenio de Bruselas de $1924^{48}$.

Mientras el Convenio de Bruselas articula dentro del contrato de Transporte Marítimo de Mercancías una serie de obligaciones, cada una con un contenido especial, para las Reglas de Hamburgo existe una sola obligación (de transporte) que, entendida en sentido amplio, debe bastar para integrar dentro de su contenido una serie de prestaciones, cuya única finalidad es la consecución de un resultado: el transporte.

El tratamiento dado por la Convención de Bruselas a comienzos del siglo XX coincide con el conflicto de intereses que en ese momento se presentaba, en el cual existía un sector armador económicamente poderoso que, apoyado en una larga tradición jurídica, imponía un derecho que establecía obligaciones con un tratamiento diferente al derecho común en forma de hacerlo más beneficioso a sus intereses. De esta manera, la Convención de Bruselas establece en el artículo 3-1 la obligación de navegabilidad, que le exige al porteador la realización de una conducta diligente, substancialmente diferente a la navegabilidad como resultado que se exigía en la legislación anterior (Código de Comercio). Igualmente, el artículo 3-2 de la misma Convención consagra la obligación de custodia y conservación de la mercancía, cuyo incumplimiento solo puede generar la responsabilidad del naviero en cuanto le sean imputables a título de culpa.

Podemos afirmar que el Convenio de Bruselas establece una estructura plural de las obligaciones del porteador por la celebración del Contrato de Transporte Marítimo de Mercancías, mecanismo diverso al ofrecido por el derecho común. La existencia de un denominado particularismo o aún más autonomía del derecho marítimo, justificado en las peculiares circunstancias que rodean la navegación, permitían fundamentar con éxito una orientación en este sentido y consagrar, bajo esta idea, instituciones claramente favorables a los intereses navieros.

Por su parte, las Reglas de Hamburgo responden a condiciones totalmente diferentes. Dentro de los organismos internacionales como la UNCITRAL, se manifiestan con mayor fuerza las reivindicaciones e intereses de los países en vías de desarrollo, que pugnan por un mayor equilibrio en las prestaciones de transporte. Simultáneamente, el proceso de

48 Cfr. Sánchez Calero (1981) p. 22; Matilla (1981) pp. 287 y ss.; Sáenz García (1992) p. 170. 
globalización de la economía mundial coincide con la necesidad de alcanzar un derecho uniforme a nivel internacional. Se inicia un período de acercamiento entre los distintos regímenes reguladores de los transportes.

Las Reglas de Hamburgo se insertan en ese proceso de acercamiento a otras formas de transporte, del cual se obtiene una regulación más sencilla y técnicamente más elabora$\mathrm{da}^{49}$. Prescinde de las distinciones que otorgaban contenidos específicos a obligaciones concretas y establece una única obligación respecto de la cual giran las demás prestaciones que se convierten en instrumentales de la primera.

En un terreno práctico su elaboración responde mejor a las necesidades contemporáneas del transporte de mercancías por mar. Actualmente, la parte interesada en el transporte de la mercancía que contrata con el porteador poco le importan las condiciones de navegabilidad de un buque específico o si ha seguido tal o cual ruta de navegación. Al cargador le interesa es la producción de un resultado concreto: que se le entregue la mercancía a él o a quien él designe en el puerto de destino y dentro de un plazo razonable, es decir que se realice el transporte como un resultado.

La consagración de una única obligación de transporte (Artículos 1-6 y 5-1 de las Reglas de Hamburgo) nos lleva a considerar el papel de las demás obligaciones que tradicionalmente se entendía hacían parte de la contratación marítima de mercancías. ¿Acaso debemos entender que han desaparecido en esta estructura o simplemente ha disminuido su protagonismo? Al igual que la mayor parte de la doctrina que trata este problema, considero que estas prestaciones, como parte que son del concepto transporte de mercancías, no desaparecen sino que se integran en un concepto general ${ }^{50}$. No podemos dudar que las conductas que tienden al establecimiento de la navegabilidad del buque, a la custodia y conservación de la mercancía o a la entrega de la misma una vez realizado el transporte son acciones esenciales al hecho mismo del transporte. Si bien bajo el régimen anterior se les había dado un contenido específico a fin de favorecer determinados intereses, otorgándoles autonomía e independencia, es perfectamente posible que bajo las Reglas de Hamburgo dicha especialidad ceda en favor de una integración al concepto general de transporte.

De esta forma, todas estas prestaciones, así como el contenido interpretativo que conllevan, mantienen su vigencia para efectos de determinar el cumplimiento o incumplimiento de la obligación de transporte ${ }^{51}$. En caso de incumplimiento imputable, el porteador responderá no por falta a la navegabilidad o custodia de la mercancía sino por la no realización de un resultado de transporte.

\section{SISTEMA DE OBLIGACIONES EN LAS REGLAS DE ROTTERDAM DE 2008}

Problemas para obtener la ratificación generalizada de las Reglas de Hamburgo de 1978, así como la necesidad de actualizar el derecho del transporte de mercancías a nivel

49 Cfr. Sánchez Calero (1981) p. 23.

50 Por todos Cfr. Sáenz García (1992) p. 173; (1984) p. 113; Bonassies (1989) p. 970.

51 En contra Berlingieri, para quien la vigencia de las Reglas de Hamburgo impide la aplicación de la interpretación que la jurisprudencia había hecho sobre determinados puntos. Así ocurre por ejemplo, con el carácter no delegable que la jurisprudencia había asignado a la obligación de navegabilidad. Cfr. BerLingIERI (1978) p. 40. 
mundial, bajo la idea de hacerlo congruente con la realidad tecnológica y de mercado del transporte marítimo de comienzos del siglo $\mathrm{XXI}^{52}$, incitaron a las partes interesadas en el transporte marítimo de mercancías a proponer la elaboración de un nuevo convenio internacional, que finalmente logre el propósito de constituir una normativa uniforme a nivel internacional reemplazando reglas que por el paso del tiempo y las aparición de nuevas circunstancias exigen una reforma inmediata.

Esta nueva normativa fue aprobada por la Comisión de Naciones Unidas en el año 2008 y es conocida como las Regla de Rotterdam. Son diversos los ámbitos que regulan las Reglas de Rotterdam, sin embargo, ateniéndonos al interés de este artículo concentraremos nuestra atención al tratamiento que se otorga a las obligaciones en el contrato de transporte marítimo de mercancías. Como veremos a continuación, ya en este punto existe una diferencia sustancial con la regulación establecida en el Convenio de Bruselas de 1924, que se concentra específicamente en la responsabilidad del porteador marítimo, y también en las Reglas de Hamburgo de 1978, que aunque regulan de manera general las obligaciones del porteador marítimo, no lo hacen con el mismo detalle y profundidad como lo reglamentan las Reglas de Rotterdam de 2008.

A diferencia del Convenio de Bruselas de 1924, que basa su aplicación en el documento que se expide con ocasión al transporte marítimo, las Reglas de Rotterdam consagran un criterio más amplio. Independientemente del documento que se expida se aplican a todos los contratos de transporte en los que el lugar de entrega de la mercancía por el remitente y el puerto de carga de dicha mercancías se encuentre situado en un Estado diferente al del puerto de descargue y lugar de entrega de la mercancía al destinatario ${ }^{53}$.

La normativa establecida en el convenio se aplicará en cuanto el lugar de recepción de la mercancía para su transporte o de entrega de la mercancía al destinatario o bien el puerto de carga o el de descarga se encuentren situados en un Estado contratante, es decir que haya ratificado el convenio.

Como afirmábamos anteriormente el convenio se aplica cuando este presente un contrato de transporte. El artículo 1 del convenio establece que contrato de transporte es

\footnotetext{
52 "La utilización de contenedores como procedimiento a menudo requiere la utilización de diferentes modalidades de transporte para hacer posible un traslado "puerta a puerta" conforme a un único contrato de transporte. Sin embargo, los periodos de responsabilidad del transportista contemplados por los actuales regímenes jurídicos en materia de transporte de mercancías por vía marítima no pueden incorporar ese tipo de traslados: se limita a la cobertura puerto a puerto en el caso de las Reglas de Hamburgo, y de "gancho a gancho" (desde el momento de la carga hasta el momento de la descarga) en el caso de las Reglas de La Haya y de La HayaVisby. El comercio moderno se basa cada vez más en transacciones de las que no se deja constancia en papel. Ninguno de los convenios vigentes ofrece una base jurídica fiable para reemplazar los documentos de transporte tradicionales por documentos de transporte electrónicos, más eficaces". Cfr. LANNAN (2012) en IllesCas y Alba FERNÁNDEZ (edits.)pp. 19-37.

53 "Al tratar de encontrar soluciones, en un seminario celebrado en Londres a comienzos de 2004 se plantearon 3 alternativas. A saber: el enfoque documentario; el enfoque contractual, y el enfoque del tráfico. En el enfoque documentario sería necesario un documento de transporte particular, como sucede con las Reglas de La Haya (un conocimiento de embarque o cualquier otro documento representativo similar). En el enfoque contractual han de especificarse el tipo o los tipos de contrato, como las pólizas de fletamento. En el enfoque comercial se distinguirían en función del tipo de tráfico, por ejemplo, entre el tráfico regular y el no regular". Cfr. HoNKA (2012) en Illescas y Alba (edit.) pp. 39-51.
} 
todo contrato en virtud del cual un porteador se compromete, a cambio del pago de un flete, a transportar mercancías de un lugar a otro. En todo caso el transporte realizado deberá prever una fase marítima aunque podrá también prever otras modalidades de transporte.

En virtud del artículo 1 mencionado, las Reglas de Rotterdam abren la puerta a una regulación uniforme en materia de transporte que involucre diversas modalidades de transporte, diferenciándose en este punto de convenios anteriores como el de Bruselas de 1924 que se aplicaba exclusivamente a la fase de transporte marítimo.

Atendiendo a intereses principalmente navieros, las Reglas de Rotterdam integran dentro del contrato de transporte la figura del denominado contrato de volumen, entendiéndose por tal todo contrato que prevea el transporte de una determinada cantidad de mercancías en sucesivas remesas durante el periodo en él convenido.

Se trata de una modalidad de transporte que pretende atender necesidades de sectores cargadores que requerían del transporte de sus mercancías durante un periodo determinado ${ }^{54}$. El objetivo de regular este tipo de transporte es, además de integrarlo como figura típica en el abanico de contratos regulados expresamente en el convenio, dar un tratamiento especial a este tipo de acuerdos exceptuándolos del cumplimiento de las reglas imperativas establecidas para este tipo de contratos en general, según la tradición jurídica en la materia establecida principalmente desde el Harter Act norteamericano del año 1893.

Una vez establecido el ámbito de aplicación del convenio veamos el tratamiento que da a las obligaciones que se generan por razón del contrato. El artículo 11 de las Reglas establecen para el porteador la obligación de transporte de las mercancías hasta el lugar de destino y su entrega final al destinatario. A semejanza de la regulación en las Reglas de Hamburgo, Rotterdam establece una obligación general de transporte de mercancías, entendiéndolas como una obligación de resultado.

Igualmente, en el artículo 13, se establecen como obligaciones específicas la recepción, carga, manipulación, estiba, transporte, conservación, custodia, descarga y entrega de las mercancías la diligencia y el cuidado debidos, permitiéndose la posibilidad de estipular que la carga, manipulación, estiba o descarga de la mercancía seas efectuadas por el cargador, el cargador documentario o el destinatario ${ }^{55}$, si así lo establecen las partes en el contrato.

Respecto a la obligación de navegabilidad, el convenio establece en el artículo 14 el deber de debida diligencia antes, al comienzo y durante el viaje por mar para poner y mantener el buque en adecuado estado de navegabilidad (tripular, armar y aviatuallar debidamente el buque y mantenerlo así durante todo el viaje-seaworthiness; y mantener en condiciones las bodegas y demás partes del buque en donde se transporten las mercancías,

\footnotetext{
54 En determinados casos cuando los actores comerciales están en relativa igualdad de condiciones, en lo que respecta a su poder de negociación, se pueden permitir ciertas libertades a las partes contratantes. Las disposiciones sobre contratos de volumen permiten a los cargadores de un determinado tamaño y categoría, que envían una gran cantidad de mercancías en varios viajes, negociar con el porteador disposiciones contractuales distintas de las imperativas conforme al Convenio. Cfr. Lannan (2012) p. 36.

55 Según el artículo 1 del convenio se entiende por "cargador" la persona que celebre un contrato de transporte con el porteador. Por "cargador documentario" la persona, distinta del cargador, que acepte ser designada como "cargador" en el documento de transporte o en el documento electrónico de transporte y "destinatario", la persona legitimada para obtener la entrega de las mercancías en virtud de un contrato de transporte o en virtud de un documento de transporte o de un documento electrónico de transporte.
} 
así como todo contenedor suministrado por el porteador en estado adecuado para la recepción, transporte y conservación de las mercancías-cargoworthiness).

En lo que se refiere a la entrega de la mercancía, las Reglas de Rotterdam regulan este deber según si se ha emitido un documento electrónico y negociable o no ${ }^{56}$. El artículo 45 del convenio regula la entrega de la mercancía una vez concluido el transporte cuando no se ha emitido un documento electrónico o un documento de transporte negociable. En estos eventos la denominada "parte controladora" ${ }^{57}$ deberá facilitar al porteador los datos del destinatario de la mercancía quien al momento de retirar la mercancía deberá identificarse frente al porteador. Si la mercancía no se entrega por falta de reclamación del destinatario, porque este no se identifica al porteador o bien este no consigue tras "un esfuerzo razonable” localizarlo, el porteador deberá solicitar instrucciones sobre qué hacer con las mercancías inicialmente a la parte controladora, en su ausencia al cargador o al cargador documentario. El cumplimiento de las instrucciones impartidas al porteador según el proceso mencionado libera de responsabilidad al porteador.

Por otro lado, si el contrato de transporte se documenta a través de un documento de transporte no negociable que deba ser restituido, el artículo 46 establece igualmente que el porteador deberá entregar la mercancía objeto del contrato al destinatario previa identificación y presentación del documento que acredita el transporte. Si el documento no negociable integra varios originales, el legitimado por el documento podrá presentar cualquiera de ellos, perdiendo los demás su validez y eficacia.

En los contratos de transporte documentados por vía electrónica o negociables, el artículo 46 del convenio exige su presentación por quien esté debidamente legitimado, para exigir la entrega de la mercancía en las instalaciones del porteador. Existe también la posibilidad de que el documento, siendo electrónico y negociable, se haya expedido en varios originales. En estos eventos la norma prevé que la presentación de cualquiera de ellos y la correspondiente entrega de la mercancía producirá la invalidez e ineficacia de los otros ejemplares.

Si el documento electrónico o negociable se ha expedido bajo la condición de que la entrega de los efectos transportados se podrá efectúa sin necesidad de presentación al porteador del respectivo documento y no se produce dicha entrega por falta de reclamación del destinatario según las condiciones pactadas o por falta de identificación del mismo al momento de su presentación, el porteador deberá, en virtud del artículo 46, informar de tal situación al cargador, en su defecto al cargador documentario, quienes podrán darles las instrucciones necesarias.

\footnotetext{
56 Las Reglas de Rotterdam regulan de manera detallada la obligación de entrega con el objetivo de facilitar al cargador la posesión inmediata de las mercancías, sin que pueda considerarse suficiente la mera puesta a disposición. Cfr. Sáenz García (2010) en Emparanza (edit.) pp. 111-137.

57 Según el artículo 1 del convenio se entenderá por "parte controladora” la persona que con arreglo al artículo 51 del convenio esté legitimada para el ejercicio del derecho de control. De acuerdo con artículo 51 el cargador será la parte controladora, salvo que, al concluir el contrato de transporte, haya designado parte controladora al destinatario, al cargador documentario o a alguna otra persona. Si se ha emitido un documento de transporte negociable o un documento electrónico será parte controladora el tenedor del documento o, de haberse emitido más de un documento negociable original, el tenedor de todos ellos.
} 
Ante la presencia de un documento electrónico o negociable que no exige su presentación, el porteador, para cumplir con las instrucciones dadas podrá exigir el otorgamiento de una garantía adecuada que ampare su eventual responsabilidad por el cumplimiento de las instrucciones recibidas.

En referencia a la protección de terceros que hubiesen adquirido el documento negociable con posterioridad a la entrega de las mercancías, el convenio establece que si ese tercero ha tenido conocimiento de la entrega realizada o si "razonablemente" hubiera podido tenerlo (porque por ejemplo en el documento mismo aparecen el momento estimado de la llegada y la forma de acceder a la información de la entrega), tendrá los derechos que incorpore el documento salvo a la entrega de la mercancía. En caso contrario adquiere todos los derechos que le otorgue el título.

Finalmente, en lo que se refiere a la entrega, las Reglas de Rotterdam (artículo 48) también regulan los eventos de falta de entrega de la mercancía porque el destinatario no acepta la entrega, o bien porque no se puede localizar e informar a la parte controladora, o al tenedor, al cargador o cargador documentario, o porque el porteador deniega justificadamente la entrega o porteador no está autorizado por la ley del lugar para realizar la entrega o en presencia de cualquier otra imposibilidad de realizarla. En cualquiera de estas situaciones el porteador podrá adoptar por cuenta y riesgo de la persona con derecho a la entrega la adopción de las siguientes medidas: almacenar las mercancías en algún lugar adecuado, desembalarlas y tomar otras medidas para su traslado, venderlas o destruirlas según los procedimientos legales del lugar y previo aviso a la persona que aparezca en el contrato como destinatario, parte controladora o cargador.

Las medidas que adopte el porteador siguiendo los criterios antes indicados, le liberarán de responsabilidad por cualquier pérdida o daño que sufran las mercancías, salvo aquellas que se causen por su culpa al no haber adoptado "medidas razonables" 58 .

\footnotetext{
58 Con fecha 23 de noviembre de 2013 fue presentado al Congreso de los Diputados en España un Proyecto de Ley de Navegación Marítima. Por ser de interés este documento, en la medida que pretende modificar la normativa vigente, debemos hacer alguna referencia a su contenido en lo que se refiere a la regulación del transporte marítimo de mercancías. En el título IV del proyecto de ley que se denomina "De los contratos de utilización del buque" se regula en el capítulo II el "contrato de fletamento", entendiendo por este, como aquel contrato en el que "se obliga el porteador, a cambio del pago de un flete, a transportar por mar mercancías y entregarlas al destinatario en el puerto o lugar de destino” (artículo 203). En primer lugar debemos mencionar que ante el tradicional debate en derecho español sobre la naturaleza jurídica del fletamento, el proyecto de ley afirma la naturaleza de transporte de este contrato, a tal punto que establece una equivalencia entre ambos contratos, el de fletamento y el de transporte marítimo de mercancías. En segundo lugar, en el fletamento se destaca la existencia de una obligación de transporte para el porteador, entendida como una obligación de resultado. Basándose en un único tipo de contrato de fletamento, el proyecto establece como clases de este contrato el fletamento por tiempo, el fletamento por viaje, el fletamento para el transporte de mercancías determinadas en régimen de conocimiento de embargue y el contrato de volumen. Cuando regula las obligaciones del contrato de fletamento establece igualmente una serie de obligaciones especiales, sin diferenciar claramente para qué tipo de contrato resultan aplicables: la obligación de puesta a disposición del buque (artículo 211), la obligación de navegabilidad (artículo 212), la obligación de carga y estiba de la mercancía (artículo 218), la obligación de entregar el conocimiento de embarque al cargador una vez la mercancía esté a bordo del buque (artículo 246), la obligación de emprender el viaje y realizarlo sin demora innecesaria y por la ruta pactada (artículo 220), la obligación de custodia de la mercancía (artículo 223), la obligación de desestibar y descargar la mercancía sin demora (artículo 227) y la obligación de entregar la mercancía al destinatario (artículo 228). Si bien resulta
} 


\section{CONCLUSIONES}

1. Son normativas vigentes en España, reguladoras del transporte marítimo de mercancías, las contenidas en el Código de Comercio y en las Reglas de La Haya-Visby, introducidas en la legislación interna a través de la Ley de Transporte Marítimo de 1949. España ratificó el Convenio de Bruselas de 1924 y posteriormente promulgó la Ley de Transporte Marítimo de 1949. Aunque no ha promulgado una ley que incorpore los protocolos modificatorios del Convenio de 23 de febrero de 1968 y 21 de diciembre de 1979, ambas normativas internacionales sí han sido objeto de ratificación (BOE de 11 de febrero de 1984). Esta superposición normativa ha generado dificultades y conflictos al momento de aplicar la normativa vigente, que debe necesariamente considerar la incorporación del Código de Comercio español como regla subsidiaria.

2. Los posibles conflictos de interpretación normativa en el caso español deben resolverse aplicando de manera prevalente la legislación especial establecida en 1949 (Ley de Transporte Marítimo), que consagra un sistema imperativo para la responsabilidad del porteador marítimo en un marco de uniformidad internacional. En este sentido, teniendo en cuenta la fuerte influencia anglosajona del contenido del Convenio de Bruselas de 1924, deben ser tenidas en cuenta las soluciones dadas en el sistema del Common law para interpretar y aplicar la normativa española vigente.

3. Colombia, aunque no ha ratificado ningún convenio internacional sobre la materia, sí ha incorporado, en la regulación del Código de Comercio, instituciones reconocidas y reguladas por el Convenio de Bruselas de 1924. Por lo tanto, la interpretación que otros países den a este instrumento jurídico resulta pertinente en el caso colombiano, también dentro de un marco de uniformidad internacional establecido también por la frecuente utilización de formularios contractuales que se remiten a esta normativa internacional. Igualmente, el artículo 7 del Código de Comercio colombiano establece la posibilidad de aplicar en el marco jurídico colombiano los tratados o convenciones no ratificadas por Colombia, entre ellos los referentes a transporte marítimo de mercancías, cuando no resultasen aplicables ninguna de las reglas establecidas en los artículos 1 a 6 del Código.

4. Frente a la discusión tradicional, dada especialmente en el derecho español, sobre la naturaleza jurídica del fletamento como contrato regulador del transporte marítimo de mercancías, parece abrirse paso la consideración de este contrato incorpora una obligación fundamental de transporte frente a otras interpretaciones que lo remiten al arrendamiento. La obligación fundamental de transporte integraría el concepto de conducción de las mercancías al lugar de destino y entrega de las mismas, tal como viene regulado en el Código

conveniente regular las eventualidades que se puedan presentar durante la operación de transporte en aras de una mayor claridad y consecuente seguridad jurídica, se echa de menos un tratamiento de mayor técnica jurídica que permita adscribir cada una de las consecuencias de la regulación de estas obligaciones a específicos contratos de transporte. De hecho existen determinados contratos de transporte en los que lo fundamental es la consecución del resultado específico entrega de la mercancía en el lugar y momento pactado, sin que tenga especial relevancia consideraciones como el buque en el que se realiza la logística de la operación de transporte. Existirán por el contrario otros supuestos en los que estas consideraciones sí resultan relevantes como en los contratos de fletamento por tiempo, por viaje y en los contratos de volumen. 
de Comercio colombiano y los instrumentos internacionalmente vigentes, o con vocación futura de regulación de la materia, como es el caso de las Reglas de Rotterdam de 2008.

5. Por virtud de la celebración de un contrato de transporte marítimo de mercancías surge para el porteador la obligación de transporte, entendida como una obligación compleja, que integra distintos deberes. La realización de estos deberes por parte del porteador marítimo conducen a la finalidad económica del contrato, que desde la perspectiva del cargador o destinatario, implica la recepción de la mercancía en el lugar de destino.

6. El deber de custodia y conservación de las mercancías tiene su fundamento en el derecho romano en la responsabilidad ex recepto, por la cual debe restituirse la cosa entregada en las mismas condiciones en que fue recibida. Para el derecho inglés, la posición del porteador es similar a la de un depositario ordinario (common bailee). Para el derecho español y colombiano el deber de custodia o conservación de la mercancía hace parte de la obligación de transporte y su incumplimiento conlleva la correspondiente responsabilidad del porteador, sin que este pueda alegar que se trata de una falta no comercial.

7. El cumplimiento del deber de entrega de la mercancía en el destino pactado, implica para el porteador la realización de la obligación de transporte. En el estado actual del derecho podemos entender que la entrega en materia de transporte marítimo de mercancías implica la transferencia de la tenencia o posesión de la mercancía antes que la transferencia de la propiedad. La tendencia actual en materia internacional, establecida particularmente en las Reglas de Rotterdam de 2008, es regular exhaustivamente este deber para dar cabida a diferentes supuestos que permitan delimitar claramente la responsabilidad y los riesgos de los actores implicados, generar condiciones que permitan facilitar el comercio electrónico y ofrecer mejores estándares de seguridad jurídica.

\section{BIBLIOGRAFÍA CITADA}

Abuauad Dagach, Ricardo (2007): Limitación de responsabilidad de la empresa naviera constitución del fondo de limitación (Santiago de Chile, Editorial Jurídica de Chile).

Albaladejo, Manuel (1994): Derecho Civil III. Vol. I - Parte general y Derecho de propiedad (Barcelona, Editorial Bosch, octava edición).

Arroyo, Ignacio (1985): "El derecho marítimo", en Estudios de Derecho Marítimo. Tomo I (Barcelona, Editorial Bosch), p. 63.

Arroyo, Ignacio (1985): "Relación entre póliza de fletamento y conocimiento de embarque: la cláusula de incorporación”, Estudios de Derecho Marítimo. Tomo I (Barcelona, Editorial Bosch).

Auchter, Gérard (1979): "La Convention des Nations - Unies sur le transport de marchandises par mer de 1978 (Règles de Hambourg, 1978)”, European Transport Law: p. 12.

Berlingieri, Francesco (1978): La disciplina della responsabilità del vettore di cose (Varese, Ed. Giuffrè).

BerLingieri, Francesco (2012): "La disciplina de las obligaciones del porteador y su responsabilidad en las Reglas de Rotterdam”, en Illescas Ortiz, Rafael y Alba Fernández, Manuel (edit.), Las Reglas de Rotterdam: una nueva era en el derecho uniforme del transporte - Actas del Congreso Internacional (Madrid, Editorial Dykinson S.L.) pp. 53-100. 
Bonassies, Pierre (1989): "La responsabilité du transporteur maritime dans les règles de la Haye et dans les règles de Hambourg", Il Diritto Marittimo, N 91: pp. 949-978.

Broseta Pont, Manuel (2012): Manual de Derecho Mercantil. Vol. II. (Madrid, Ed. Tecnos, decimonovena edición)

Brunetti, Antonio (1950): Derecho Maritimo Privado, Tomo I (Barcelona, Editorial Bosch).

Carvajal, Patricio-Ignacio (2009): "La persistencia de recipere en su acepción de prometer y la desvinculación entre vis maior y la exceptio labeonis en época postclásica: salvum recipere obligare y suscipere in fidem suam" en Studi in onere di Antonino Metro (Ed. Giuffrè, tomo I) pp. 409-450.

Chanda, Soumy Adipta (2012): "A comparison of rights and liabilities under a charter party and a bill of lading", University of San Francisco Maritime Law Journal, № 24: pp. 65-82.

Chaveau, Paul (1958): Traité de Droit Maritime (Paris, Editorial Libr. Techniques).

Chorley, Robert Samuel (1992): Shipping Law/Njj Gaskell, C. Debattista, Rj Swatton (London, Ed. Pitman, octava edición).

Colinvaux, Raoul (1982): Carver's Carriage by Sea. Vol. I. (London, Ed. Stevens \& Sons, decimotercera edición).

Costa, F. P. (1986): "Inquadramento dell'obbligo di diligenza del vettore nella custodia delle merci fino al deposito liberatorio", Il Diritto Marittimo: pp. 883 y ss.

Díez-Picazo, Luis (1993): Fundamentos de Derecho Civil Patrimonial - Las relaciones obligatorias (Madrid, Ed. Civitas, Vol. II, cuarta edición).

ECHEVARría Rivera, Luis Eduardo (1983): El transporte maritimo-enciclopedia sucinta de las ramas del derecho que lo regulan (Pamplona, Editorial Aranzadi, segunda edición).

Girón Tena, José (1959): El naviero: directrices actuales de su régimen jurídico (Bilbao, Editorial Publicaciones Universidad de Deusto).

Gómez Segade, José Antonio (1980): "El transporte marítimo de mercancías: de las Reglas de La Haya a las Reglas de Hamburgo", Revista de Derecho Mercantil, № 156: pp. 221-244.

GonZÁlez Castillo, Joel (2011): "Las cláusulas limitativas, exonerativas o agravantes de responsabilidad en materia contractual. Validez y límites". Revista Chilena de Derecho, vol. 38 No 1: pp. 89-100.

HeRnández Martí, Juan (1984): Contrato de transporte marítimo de mercancías (Valencia).

Honka, Hanny (2012): "Las reglas de Rotterdam. Contrato de transporte y ámbito de aplicación”, en Illescas Ortiz, Rafael y Alba Fernández, Manuel (edit.), Las Reglas de Rotterdam: una nueva era en el derecho uniforme del transporte - Actas del Congreso Internacional (Madrid, Editorial Dykinson) pp. 39-51.

Ivamy, E. R. Hardy (1989): Payne \& Ivamy's Carriage of Goods by Sea (Londres-Edimburgo, Ed. Butterworths, decimotercera edición) pp. 87-88.

Jiménez Valderrama, Fernando (1999): “La obligación de proveer la navegabilidad del buque en el Convenio de Bruselas de 1999", Revista Dikaion, No 8: pp. 165-85.

La Cruz Verdejo, José Luis et al. (1990): Elementos de Derecho Civil III - Derechos Reales. Vol. I. (Barcelona, Ed. Bosch, tercera edición).

Lannan, Kate (2012): "Navegando por las reglas de Rotterdam”, en Illescas Ortiz, Rafael y Alba Fernández, Manuel (edit.), Las Reglas de Rotterdam: una nueva era en el derecho 
uniforme del transporte - Actas del Congreso Internacional (Madrid, Editorial Dykinson) pp. 19-37.

Lefebvre D’Ovidio, A. y Pescatore, G. (2011): Manuale di diritto della navigazione (Milano, Editorial Giuffrè, duodécima edición).

MancA, Plinio (1970): International Maritime Law. Vol. II. (Antwerpen, European Transport Law)

Mapelli, Enrique (1987): Régimen Jurídico del Transporte (Madrid, Ed. Centro de Publicaciones del Ministerio de Justicia).

Matilla Alegre, Rafael (1981): "Reglas de Hamburgo: principios fundamentales”, Revista General de Legislación y Jurisprudencia, tomo LXXXII: pp. 287.

Matilla Alegre, Rafael (1988): Contrato de utilización del buque. Lecciones (Barcelona, Editorial Bosch).

MÉNAger, Leon-Robert (1960): “"Naulum» et «Receptum rem salvam fore» contribution a l'etude de la responsabilité contractuelle dans les transports maritimes en droit romain”, Revue Historique de Droit Français et Étranger, 4a serie, año 38 : pp. 398-435.

MocatTa, Alan y otros (1984): Scrutton on Charterparties and Bills of Lading (London, Ed. Sweet \& Maxwell, decimal novena edición).

Pardessus, J.M. (1845): Collection de lois maritime antériures au XVIIIe siècle. Tomo IV. (Paris, Editorial L'imprimerie royale).

PelÁez, Manuel (1982): "Los contratos de fletamento en el derecho histórico catalán", Anuario de Derecho Maritimo. Vol. II. (Madrid, Editorial Karpos)

Quintana CaRlo, Ignacio (1977): La responsabilidad del transportista aéreo por daños a los pasajeros (Salamanca, Editorial Universidad de Salamanca).

Recalde Castells, Andrés (1992): El conocimiento de embarque y otros documentos del transporte - Función representativa (Madrid, Editorial Cívitas).

Righetti, Giorgio (1987): Trattato di Diritto Marittimo. $1^{\text {a }}$ parte, Tomo II. (Milano, Editorial Giuffrè).

Rubio Garrido, Tomás (1993): Contrato de compraventa y transmisión de la propiedad (Bolonia, Editorial Publicaciones del Real Colegio de España).

Rubio, Jesús (1953): El fletamento en el derecho español (Madrid, Editorial Revista de Derecho Privado).

Sáenz García de Albizu, Juan Carlos (1992): La innavegabilidad del buque en el transporte maritimo (Madrid, Ed. Cívitas).

Sáenz García de Albizu, Juan Carlos (2010): "Las obligaciones del porteador hasta la entrega de las mercancías en destino”, en Emparanza Sobejano, Alberto (edit.), Las Reglas de Rotterdam - la regulación del contrato de transporte internacional de mercancías por mar (Madrid, Editorial Marcial Pons) pp. 111-137.

SÁenz García de Albizu, Juan Carlos (2010): "Las obligaciones del porteador hasta la entrega de las mercancías en destino", en Emparanza, Alberto (edit.), Las Reglas de Rotterdam - la regulación del contrato de transporte internacional de mercancías por mar (Madrid, Editorial Marcial Pons) pp. 111-137.

Sánchez Calero, Fernando (1957): El contrato de transporte marítimo de mercancías (Roma-Madrid, Ed. Consejo Superior de Investigaciones Científicas). 
Sánchez Calero, Fernando (2004): Instituciones de Derecho Mercantil. Tomo II. (Madrid, Ed. Mc GrawHill, vigésima sexta edición).

Wilson, John (1993): Carriage of Goods by Sea (London, Editorial Pitman Publishing, segunda edición).

\section{NORMAS CITADAS}

Ley española de 22 de diciembre de 1949 de transporte marítimo de mercancías en régimen de conocimiento de embarque (BOE no 358 de 24 de diciembre de 1949).

Ley francesa No 66-420 de 18 de junio de 1966 de contratos de fletamento y transporte marítimo (JORF de 24 de junio de 1966, pág. 5206).

Código de Comercio colombiano (Decreto 410 de 1971 de 27 de marzo).

Código de Comercio chileno (Santiago, 23 de noviembre de 1865).

Código italiano de la navegación (R.D. 3 marzo de 1942, n. 327 - edición especial a la Gazzetta Ufficiale n. 93 del 18 de abril de 1942).

British Carriage of Goods by Sea Act 1971 de 8 de abril.

Proyecto de Ley de Navegación Marítima. Presentado al Congreso de los Diputados (España) el 23 de noviembre de 2013.

\section{CONVENIOS INTERNACIONALES CITADOS}

Convenio internacional para la unificación de ciertas reglas en materia de conocimiento de embarque (Reglas de La Haya) (Bruselas, 25 de agosto de 1924).

Protocolo modificativo del Convenio internacional para la unificación de ciertas reglas en materia de conocimiento de embarque (Reglas de Visby) (Bruselas, 23 de febrero de 1968).

Protocolo modificativo del Convenio internacional para la unificación de ciertas reglas en materia de conocimiento de embarque, enmendado con el Protocolo modificativo de 1968 (Bruselas, 21 de diciembre de 1979).

Convenio de Naciones Unidas sobre transporte marítimo de mercancías (Reglas de Hamburgo) (Hamburgo, 31 de marzo de 1978).

Convenio de Naciones Unidas sobre el contrato de transporte internacional de mercancías total o parcialmente marítimo adoptado en Asamblea General el 11 de diciembre de 2008 (Reglas de Rotterdam). 
